Illinois State University

ISU ReD: Research and eData

Theses and Dissertations

3-19-2019

\title{
The Moderating Effect of Employee Bottom-Line Mentality on the Relation between Personality and Unethical Pro-Organizational Behaviors
}

Jordan Thomas

Illinois State University, jpthoma@ilstu.edu

Follow this and additional works at: https://ir.library.illinoisstate.edu/etd

Part of the Organizational Behavior and Theory Commons, Social and Behavioral Sciences Commons, and the Vocational Rehabilitation Counseling Commons

\section{Recommended Citation}

Thomas, Jordan, "The Moderating Effect of Employee Bottom-Line Mentality on the Relation between Personality and Unethical Pro-Organizational Behaviors" (2019). Theses and Dissertations. 1107.

https://ir.library.illinoisstate.edu/etd/1107

This Thesis is brought to you for free and open access by ISU ReD: Research and eData. It has been accepted for inclusion in Theses and Dissertations by an authorized administrator of ISU ReD: Research and eData. For more information, please contact ISUReD@ilstu.edu. 


\section{THE MODERATING EFFECT OF EMPLOYEE BOTTOM-LINE MENTALITY ON THE RELATION BETWEEN PERSONALITY AND UNETHICAL}

PRO-ORGANIZATIONAL BEHAVIORS

\section{JORDAN THOMAS}

\section{Pages}

Unethical pro-organizational behavior (UPB) refers to unethical actions that employees engage in to benefit the company they work for. The issue of employees engaging in UPB has been highlighted in various high-profile scandals, such as the Volkswagen emissions scandal. The current study examined the interaction between employees' personality traits, perceptions of bottom-line mentality (BLM), and UPB. The results suggested that when employees who are low on trait conscientiousness and honesty-humility are placed in an environment in which they perceive to have high levels of BLM, they are more likely to engage in UPB than those individuals who had higher levels of each of these respective traits. This study contributed to the literature in various ways, through identifying two strong trait predictors of UPB, as well as examining how these traits may interact with one's perception of BLM at their organization, to enhance their propensity to engage in acts of UPB.

KEYWORDS: unethical pro-organizational behavior, personality, traits, bottom-line mentality, counterproductive work behavior 


\title{
THE MODERATING EFFECT OF EMPLOYEE BOTTOM-LINE MENTALITY ON THE RELATION BETWEEN PERSONALITY AND UNETHICAL PRO-ORGANIZATIONAL BEHAVIORS
}

JORDAN THOMAS

\author{
A Thesis Submitted in Partial \\ Fulfillment of the Requirements \\ for the Degree of \\ MASTER OF SCIENCE \\ Department of Psychology \\ ILLINOIS STATE UNIVERSITY
}




\section{(C)2019 Jordan Thomas}


THE MODERATING EFFECT OF EMPLOYEE BOTTOM-LINE MENTALITY ON THE RELATION BETWEEN PERSONALITY AND UNETHICAL PRO-ORGANIZATIONAL BEHAVIORS

JORDAN THOMAS

COMMITTEE MEMBERS:

Alexandra Ilie, Chair

Dan Ispas 


\section{ACKNOWLEDGMENTS}

I would like to express deep gratitude to Dr. Dan Ispas for providing me with guidance throughout the entire thesis-writing process. Your constructive suggestions and mentorship was very much appreciated. Additionally, I would like to thank Dr. Alexandra Ilie for proofreading and critiquing my thesis document as well as Dr. Margaret Nauta for the feedback she provided during my thesis proposal. Lastly, I would like to thank my family and friends who have supported me throughout my study.

J. T. 


\section{CONTENTS}

Page

ACKNOWLEDGMENTS

TABLES

FIGURES

CHAPTER I: THE PROBLEM AND ITS BACKGROUND 1

Statement of the Problem 1

$\begin{array}{ll}\text { Purpose } & 4\end{array}$

CHAPTER II: REVIEW OF THE RELATED LITERATURE 6

$\begin{array}{ll}\text { General Literature Review } & 6\end{array}$

Umphress and Bingham's Model of Unethical Pro-Organizational Behavior $\quad 6$

$\begin{array}{ll}\text { Organizational Identity and UPB } & 10\end{array}$

Employee Disposition and UPB 11

Leadership and UPB $\quad 13$

Relation between UPB and CWB 17

Conscientiousness and Unethical Pro-Organizational Behavior $\quad 20$

Honesty-Humility and Unethical Pro-Organizational Behavior 23

Bottom-line Mentality and Unethical Pro-Organizational Behavior 25

CHAPTER III: RESEARCH DESIGN 29

$\begin{array}{ll}\text { Method } & 29\end{array}$

$\begin{array}{ll}\text { Participants } & 29\end{array}$

$\begin{array}{ll}\text { Measures } & 30\end{array}$

$\begin{array}{ll}\text { Unethical Pro-Organizational Behavior } & 30\end{array}$ 
$\begin{array}{ll}\text { Brief Self-Control Scale } & 36\end{array}$

$\begin{array}{ll}\text { Procedure } & 37\end{array}$

$\begin{array}{ll}\text { Data Analysis } & 37\end{array}$

$\begin{array}{ll}\text { Results } & 38\end{array}$

$\begin{array}{ll}\text { Descriptive Statistics } & 38\end{array}$

$\begin{array}{ll}\text { Hypothesis Testing } & 39\end{array}$

Hypothesis 1 - CWB and UPB $\quad 39$

Hypothesis 2 - Conscientiousness and UPB 39

Hypothesis 3 - Self-Control and UPB 39

Hypothesis 4 - Honesty-Humility and UPB $\quad 40$

Hypothesis 5a - BLM Moderates HH and UPB $\quad 40$

Hypothesis 5b - BLM Moderates Self-Control and UPB 43

$\begin{array}{ll}\text { Discussion } & 45\end{array}$

$\begin{array}{ll}\text { Practical Implications } & 51\end{array}$

$\begin{array}{ll}\text { Limitations } & 52\end{array}$

$\begin{array}{ll}\text { REFERENCES } & 55\end{array}$

APPENDIX A: CONSCIENTIOUSNESS SCALE 66

$\begin{array}{ll}\text { APPENDIX B: HONESTY-HUMILITY SCALE } & 67\end{array}$

APPENDIX C : BOTTOM-LINE MENTALITY SCALE 68

APPENDIX D : COUNTERPRODUCTIVE WORK BEHAVIOR SCALE 69 
APPENDIX F: SELF-CONTROL SCALE 


\section{TABLES}

Table

Page

1. Means, Standard Deviations, and Correlations of All Study Variables

2. Hierarchical Regression Analysis Testing the Moderating Effect of Bottom-line Mentality on Honesty-Humility and Unethical Pro-Organizational Behavior

3. Hierarchical Regression Analysis Testing the Moderating Effect of Bottom-line Mentality on Self-Control and Unethical Pro-Organizational Behavior 


\section{FIGURES}

Figure

Page

1. Standardized regression coefficients for the relationship between

conscientiousness and UPB as mediated by self-control

2. The conditional effect of honesty-humility at high, moderate, and low levels of bottom-line mentality on unethical pro-organizational behavior

3. The conditional effect of self-control at high, moderate, and low levels of bottom-line mentality on unethical pro-organizational behavior 


\section{CHAPTER I: THE PROBLEM AND ITS BACKGROUND}

\section{Statement of the Problem}

Research has found that not only are unethical acts occurring in organizations, but they are in fact flourishing (Frank et al., 2003). In light of the ever-growing and public organizational scandals, such as Enron and the Volkswagen emissions scandal, researchers have been investigating why this kind of phenomenon has been taking place. One construct that may explain why employees engage in acts such as lying to the public, cheating, and falsifying information, is unethical pro-organizational behavior (UPB). UPB was proposed by Umphress, Bingham, and Mitchell (2010) and refers to unethical acts that employees commit that are meant to benefit their company. Therefore, UPB differs from other deviant acts in that they are committed primarily with the intention of helping the organization. Despite the proorganizational nature of these acts though, they may unintentionally lead to long-term consequences for the organization, such as litigation (Umphress, Bingham, \& Mitchell, 2010).

For instance, during the Volkswagen emissions scandal, Volkswagen, a German car manufacturer, had been caught installing "cheat devices" into their vehicles, so that they could meet the U.S.' strict carbon emission standards. These cheat devices were programmed to activate when laboratory tests were being performed and would lower the amount of carbon emissions that were being expelled from the vehicle. However, once the car was brought onto the open-road, the device would turn off. In turn, the vehicle would emit carbon emissions between 30-80 times higher than the standard that was dictated by law. The upper management at this company had made the decision to install these devices, due to increasing external pressures to increase profits by opening up a new line of vehicles to a profitable market. In the end though, Volkswagen was forced to pay out $\$ 4.3$ billion in damages. This case study high-lights some of 
the core tenets of UPB; the employees (upper management) engaged in an unethical act that they believed would help the company, but their actions ultimately lead to severe ramifications in the forms of a damaged reputation and a large settlement payout (Gibney, 2018).

Research to date on UPB has primarily focused on its attitudinal antecedents, such as organizational identity (OI), as well as the influence of leadership on follower's UPB (Chen, Chen, \& Sheldon, 2016; Effelsberg, Solga, \& Gurt, 2014; Effelsberg \& Solga, 2015; Graham, Ziegert, \& Capitano, 2015; Kong, 2016; Miao, Newman, Yu, \& Xu, 2013). However, only a handful of studies have investigated the role of traits (Castille, Buckner, \& Thoroughgood, 2016; Lee et al., 2017). Collectively, these past studies have provided empirical support for the relation between traits and UPB. However, there still remains a lot to be explored. Thus, according to Castille, Bucker, and Thoroughgood (2016)," there seems to be fertile theoretical ground for considering how personality theory might complement the use of social identity and social exchange theories in the study of UPB (page 9).”

One such trait that has not been investigated yet, in the UPB literature is conscientiousness. This factor has been shown to be related to a wide-array of deviant acts across different literatures, such as CWB (Berry, Ones, \& Sackett, 2007; Salgado, 2002), criminology (Pratt \& Cullen, 2000; Vazsonyi, Mikuska, \& Kelly, 2017), as well as integrity testing (Marcus, Lee, \& Ashton, 2007; Bakker, Demerouti, \& ten Brummelhuis, 2012; Salgado J. F., 1997). Relatedly, honesty-humility, a factor under the HEXACO model of personality, has also not been investigated. Like conscientiousness, honesty-humility has strong empirical support for its relation to many unethical behaviors and their analogous acts, such as CWB (Lee, Ashton, and Shin, 2005; Lee, Ashton, and de Vries, 2005; Ashton \& Lee, 2008b; Zettler \& Hillbig, 2010). Thus, together these two traits have great potential to be robust predictors of UPB. 
Additionally, Umphress and Bingham (2011), as well as Castille et al. (2016) stressed the importance of investigating potential situational moderators of UPB's relations with its respective attitudinal and dispositional predictors, such as amoral culture and employees' perceptions of bottom-line mentality. Thus far in the literature, the only contextual variable that has been examined at length is leadership. However, little is known on how other environmental variables may interact with traits to predict UPB (Castille, Buckner, \& Thoroughgood, 2016).

Another gap in the UPB literature that needs to be addressed further is how UPB relates to other constructs, such as CWB. CWB is a well-studied organizational phenomenon in the organizational behavior literature. Generally, they have been defined as being volitional behaviors that employees engage in that violate organizational norms and may potentially harm the organization, other people in the organization, or the company's stakeholders (Marcus, Taylor, Hastings, Sturm, \& Weigelt, 2016; Robinson \& Bennett, 1995; Sackett, 2002; Spector \& Fox, 2005). Like UPB, the extent to which employees engage in CWB's are of concern companies and researchers due to its prevalence, as well as the wide-range of negative outcomes they are associated with. For instance, deviant work behaviors, such as theft, are estimated to cost companies roughly $\$ 6$ to $\$ 200$ billion annually (Murphy, 1993). Moreover, 33-75 percent of employees are estimated to have engaged in at least one form of CWB (Harper, 1990).

Despite the considerable amount of research that has been conducted on deviant behaviors in the workplace though, the literature still lacks a major organizing theoretical framework, with many of the behaviors that fall under CWB being studied separately. This lack of an organizing framework has led to the development of numerous constructs in the literature, such as anti-social behavior and workplace aggression, that attempt to explain behaviors that are subsumed within the definition of CWB (Bowling \& Gruys, 2010; Griffin \& Lopez, 2005, 
Marcus et al., 2013). In addition to the behavioral overlap that exists between these numerous constructs, further evidence for their similarlity can be found in the fact that they tend to be positively related to one another (Gruys, 1999). Thus, it seems that there exists, at a general level, a high degree of similarity among them. Therefore, it is of upmost importance that UPB's relation to these other constructs be examined, most notably CWB. Investigating UPB's relation to these other constructs will help to expand its nomological network, as well as to further examine its discriminant validity (Lee et al., 2017).

In Griffen and Lopez's (2005) review of the literature on deviant workplace behavior, they suggested that the lack of theoretical clarity among these different constructs could be addressed by investigating their common antecedents. By identifying the antecedents, it will allow researchers to provide empirical support for how their constructs differ from other more well-established constructs. In other words, if UPB and CWB are found to share similar antecedents, such as employee attitudes or traits, then it would insinuate that they are not so different from one another. This recommendation is similar to what Bowling and Gruys (2010) advocated, suggesting that if this pattern of interrelated antecedents existed among numerous constructs, it would provide support for collapsing them into one general CWB construct, rather than studying them as a specific type of behavior.

\section{Purpose}

Given the lack of research on the relation between traits and UPB, the primary focus of the current study was to investigate potential trait predictors of UPB. Specifically, honestyhumility $(\mathrm{HH})$ and conscientiousness $(\mathrm{C})$, which have been shown to be robust predictors of CWB (Berry, Ones, \& Sackett, 2007; Bolton, Becker, \& Barber, 2010; Ceschi, Sartori, Dickert, \& Costantini, 2016; Dalal, 2005; Marcus, Lee, \& Ashton, 2007; Salgado, 2002), are able to 
explain variance in a related, yet distinct construct in UPB. Furthermore, a potential mediator of the conscientiousness-UPB relation, self-control was also investigated. According to a recent meta-analysis (Vazsonyi et al., 2017), as well as Gottfredson and Hirschi's (1990) general theory of crime, self-control can be linked to many criminal behaviors and their analogous acts. Therefore, conscientiousness may be linked to UPB through one's ability to self-regulate. In addition to identifying potential trait predictors of UPB, the study also explored situational moderators of these relationships. Specifically, an employee's perception of bottom line mentality at their workplace was investigated (Greenbaum, Mawritz, \& Eissa, 2012).

Lastly, the current study examined the relation between UPB and CWB. Given the state of the literature on CWB, it is important to determine whether this relatively new construct, $\mathrm{UPB}$, is truly distinct from related deviant acts. So far, the only studies that have touched upon the relationship between these constructs was Umphress et al. (2010) in their original proposal of UPB, as well as Lee et al. (2017), who also examined a potential common antecedent, psychological entitlement. Therefore, the literature on UPB would benefit from further investigations into the shared dispositional and situational antecedents of these constructs, as well as their underlying mechanisms. 


\section{CHAPTER II: REVIEW OF THE RELATED LITERATURE}

\section{General Literature Review}

\section{Umphress and Bingham's Model of Unethical Pro-Organizational Behavior}

Unethical pro-organizational behavior (UPB) is a construct that was first described by Umphress et al. (2010) that refers to unethical acts that employees commit for the benefit of their company. The "pro-organizational" component of their definition refers to the fact that these acts are not part of an employee's formal job description and are self-motivated, meaning they are engaged in under the employee's own free will and are not ordered by a supervisor. Other boundary conditions of UPB suggest that these acts are not accidental but are committed with the intent of helping the organization. However, despite these good intentions, UPB may actually lead to serious ramifications for the company, such as litigation. Lastly, it is assumed that acts of UPB are primarily motivated by the employee's desire to help the company and not solely out of self-interest (Umphress et al., 2010).

Much of Umphress et al.'s (2010) theorizing regarding UPB had focused on exchange relationships as well as aspects of social identity theory. In their initial study, they examined how positive attitudes toward one's organization, such as organizational identity (OI), may lead to unintended outcomes like UPB. Drawing on social identity theory, they predicted that the more an employee incorporated their company into their self-concept, the more likely they would be to commit acts of UPB, through processes of internalization. In other words, if an employee perceived their company's accomplishments and failures as their own, they may be more likely to rationalize or turn a blind eye to the potential consequences of their actions.

To examine the role that exchange-based relationships had on employee UPB, Umphress et al. (2010) drew on social exchange theory, which asserted that social relationships are 
facilitated through the exchange of resources. They tested this by measuring the extent to which employees endorsed norms regarding positive reciprocity, which referred to the extent to which an individual feels obligated to return a beneficial behavior to an organization. Specifically, they predicted that positivity reciprocity beliefs would moderate the relation between organizational identity and UPB, due to the employee feeling that they needed to repay the company for the positive treatment they had received from it.

The results of their study revealed that positive reciprocity beliefs moderated the relation between OI and UPB. Specifically, it was found that when positivity reciprocity beliefs were high employees were significantly more likely to engage in UPB. To build on these results, the authors utilized a longitudinal design in a follow-up study. At the first-time point, they collected data on positivity reciprocity beliefs and OI, and at time two, they collected data on self-reported UPB. The results of the study replicated their previous finding, with positive reciprocity beliefs moderating the relation between OI and UPB. Thus, it seemed that OI in of itself wasn't enough to motivate someone to commit UPB, but when it was paired with someone who also shared high degrees of positive reciprocity beliefs, they were more likely to commit UPB.

Umphress and Bingham (2011) built on the results of their first series of studies on UPB, by incorporating a construct called neutralization into their proposed theoretical model. Neutralization refers to the process by which individuals rationalize committing unethical behaviors (Sykes \& Matza, 1957). For instance, if an employee were engaging in an act that may lead to individuals outside of the organization being harmed, such as lying about the risks associated with an experimental, yet potentially very profitable drug, they may think to themselves that they were just doing their jobs, or that the benefits (to the company) outweigh the harm that could befall those who took it. People engage in neutralization when they commit 
an unethical act to avoid experiencing cognitive dissonance (Umphress \& Bingham, 2011). Thus, neutralization allows employees to engage in morally dubious acts by masking over any potential ethical dilemmas that may exist (Rest, 1986). Then, once an employee has engaged in neutralization, ethical dilemmas merely become business decisions (Umphress \& Bingham, 2011). In addition to this cognitive mechanism of neutralization, Umphress and Bingham also incorporated the role that situational factors, such an organization's culture, may have on promoting UPB into their model.

Employing Trevino’s (1986) person-situation model of employee-organization decision making, Umphress and Bingham (2011) reasoned that a company’s amoral culture may exacerbate UPB's. Amoral culture refers to a corporate environment whose social norms enable or even encourage the use of unethical behavior. It is theorized that unethical cultures arise out of amoral leaders that emphasize the procurement of organizational goals, most notably, those that are directly tied to the company's financial success. Therefore, employees with high levels of organizational identification and endorsement of positivity reciprocity are especially vulnerable to engage in UPB when placed in an organization who turns a blind-eye to such moral dilemmas.

In addition to amoral culture, a situational moderator under Umphress and Bingham's (2011) model, the authors also identified an individual-level moderator, moral development. Their conceptualization of moral development was taken from Kohlberg's (1969) stages of cognitive development, as they relate to solving ethical dilemmas. Based off Kohlberg's stages of cognitive development, Umphress and Bingham proposed that the relation between social exchange relationships and organizational identity, would be strongest at the conventional stage. Those at this stage base their judgements of right and wrong on the norms of their social groups. 
Thus, when placed with an ethical dilemma, these individuals are more likely to have their decisions influenced by the relationships they have with those in their company.

The final components of Umphress and Bingham's (2011) model suggested that an employee who commits UPB will likely experience emotional consequences in the form of guilt and shame as well as cognitive consequences, such as cognitive dissonance. Guilt and shame are related emotions that individuals experience when they commit an unethical act (Trevino et al. 2006). When individuals experience guilt or shame, they will be less likely to engage in future UPB. Cognitive dissonance is a state that is characterized by a state of arousal that occurs when a person's behavior contradicts their self-concept, such as being a good person. To maintain a positive self-image, the individual may shift their attitudes to align with their contradictory behavior, with more extreme shifts in attitudes being associated with larger degrees of dissonance (Festinger \& Carlsmith, 1957). For example, an employee who commits UPB may adjust their view of unethical behavior through the process of neutralization. After experiencing cognitive dissonance and neutralization, Umphress and Bingham theorized that this attitudinal adjustment would, in turn, lead to enhanced social exchange relationships and organizational identification, enhancing the likelihood that the employee would commit UPB again.

Since Umphress and Bingham (2011) proposed their theoretical model of UPB, only a handful of empirical studies have investigated their hypothesized relationships. The majority of these studies have primarily focused on the effects of leadership and attitudinal antecedents, such as OI. (Chen, Chen, \& Sheldon, 2016; Kong, 2016; Effelsberg, Solga, \& Gurt, 2014; Effelsberg \& Solga, 2015; Graham, Ziegert, \& Capitano, 2015; Miao, Newman, Yu, \& Xu, 2013; Kalshoven, van Dijk, \& Boon, 2016). 


\section{Organizational Identity and UPB}

OI was conceptualized in Umphress et al. (2010) as the extent to which an employee derived their self-concept from their membership to their organization. In their initial studies on UPB, they asserted that an employee's OI may not only be related to positive outcomes, such as organizational citizenship behavior and enhanced job performance, but that it may actually motivate an employee to engage in unethical acts as well, such as UPB. This hypothesized relation between OI and UPB was partially supported in their two studies, with the authors finding that OI was related to UPB only when positivity reciprocity beliefs were high.

Interestingly though, studies that have investigated OI since Umphress et al., have found support for its relation to UPB.

For instance, Effelsberg and Solga (2013) found supervisor OI was positively related to intentions to commit UPB. Additionally, in another study, Effelsberg, Solga, and Gurt (2013) found that follower OI mediated the relationship between transformational leadership and follower UPB. Moreover, Kong (2016) also found evidence supporting OI's role as a mediator in explaining the interaction that was observed between employee's work passion and trait mindfulness on UPB.

Additional evidence for OI's relation to UPB can be found in Chen et al. (2016), who investigated the relations between OI, external competition, and one's propensity to morally disengage on UPB. Moral disengagement refers to one's propensity to rationalize and justify their unethical behaviors. They argued that individuals with higher levels of OI would be more likely to engage in UPB because they would be more likely to perceive a threat to their company, especially when intra-organizational competition was high. In turn these employees would aim to help by the company by "any means necessary." The authors' hypothesized relationships 
between external competition, moral disengagement, OI, and UPB, were all supported.

Specifically, they found that employees with high OI were the most likely individuals to commit UPB when competition was high, and that this relationship was explained through their propensity to morally disengage.

All together, these studies provide strong support to Umphress and Bingham's (2011) model, suggesting that OI plays a critical role in motivating employees to commit UPB (Chen et al., 2016; Effelsberg, Solga, and Gurt, 2013; Kong, 2016). However, OI has also been shown to act as a moderator, such as in Miao, Newman, and Xu (2013), who found that follower OI enhanced the relationship between a supervisor's ethical leadership and follower's UPB. Despite OI's prominent role, though other individual difference variables have been shown to be related to UPB, such as moral identity (Wang et al., 2017) and psychological entitlement (Lee et al., 2017).

\section{Employee Disposition and UPB}

Wang et al. (2017) examined the role of employee organization relationships in predicting UPB. Employee organization relationships were defined as, "the formal and informal, the economic, social, and psychological connection between an employee and his or her employer" (Tsui \& Wang 2002, p. 78). Through social exchange processes, the authors argued that employees will feel compelled to reciprocate the organization's positive treatment through acts of UPB. However, they suggested that this relationship would be moderated by an employee's moral identity. Moral identity refers to the extent to which employees endorse traits that are associated with being a moral person into their self-concept (Aquino \& Reed, 2002). Individuals who possess a high degree of moral identity, show enhanced moral awareness and concern for the ramifications of their actions as well as the actions of others, on both their in- 
group members, as well as on external stakeholders (Aquino et al., 2007). Thus, moral identity should weaken the positive relationship between perceptions of social exchange with one's company and UPB. The authors tested their hypotheses across two field studies. The results of their first study supported the hypothesized positive relationship between perceptions of social exchange and intention to commit UPB. To strengthen these findings, in study 2 , the authors measured employees' actual engagement in UPB, as well as the moderating role of moral identity. Their results supported the moderating effect of moral identity on perceptions social exchange and UPB. Specifically, they found that moral identity weakened the positive relationship between social exchange perceptions and UPB. These findings demonstrated that certain individual difference variables may weaken the relationship between situational forces (such as employee organization relationships and social exchange) and UPB.

Another study that examined the relation between disposition and UPB was conducted by Lee et al. (2017). In their study, they investigated the link between employees' psychological entitlement and UPB, as well as potential mediators of this relationship. Psychological entitlement was conceptualized as an enduring belief that one deserves more than others; a belief that may not actually match one's actual abilities or efforts (Campbell et al., 2004). This trait has been shown to be related to both unethical behaviors and CWB (Harvey \& Harris, 2010). The authors argued psychological entitlement should be related to UPB, due to entitled individuals being more likely to interpret their unethical behaviors as being moral (Tsang, 2002). Moreover, entitled individuals are motivated by self-serving goals, such as receiving approval and recognition from others (Rose \& Anastasio, 2014). Therefore, these individuals will be more willing to engage in UPB in an effort to achieve high status, which in turn, will help the organization. Thus, the authors acknowledged although these behaviors may be about serving the 
goals of the individual as much as the organization, they argue that in an employee's attempt to serve their organization, their actions likely reflect, to some extent, personal goals that happen to coincide with the organization's goals. In addition to their predicted positive relationship between psychological entitlement and UPB, the authors also hypothesized that OI would strengthen this association. The results of the author's analyses showed evidence to support the hypothesized positive relation between psychological entitlement and UPB, as well as the moderating role of OI.

In study 2 , the authors built upon these findings by investigating the mediating roles of status striving and moral disengagement on the relation between psychological entitlement and UPB. Status striving, as had been mentioned earlier, is characteristic of individuals with high levels of entitlement because they are motivated by a desire to be admired by others. Similarly, moral disengagement is a construct that had been shown in prior studies to mediate the relation between UPB (Chen et al., 2016) as well as a host of other unethical acts (Moore et al. 2012). The authors found support for the hypothesized indirect effects of status striving and moral disengagement. Collectively, this set of findings was important, because they helped explain why psychological entitlement is related to UPB as well as replicate the moderating role of OI.

\section{Leadership and UPB}

Many of the empirical studies that have been conducted on UPB, have examined the impact that certain leadership styles have on subordinates' unethical behaviors. For instance, Effelsberg, Solga, and Gurt (2013) investigated the influence that transformational leadership had on subordinates' intentions to commit UPB, across two longitudinal field studies, using an interactionist approach. The authors suggested that transformational leadership may unintentionally lead to UPB through the leader's ability to enhance their follower's sense of 
organizational identity (OI). In addition to the authors' hypotheses regarding transformational leadership and UPB, they also investigated whether HH and Machiavellianism moderated this relationship. Specifically, they predicted that among those with an inclination to commit unethical acts, the positive relationship between OI and UPB will be stronger. Lastly, the authors examined the mediating role of OI on the relation between transformational leadership and UPB. The results of the authors' proposed moderated-mediation model, across both of their studies, supported all of their hypotheses, with subordinates who were low on both $\mathrm{HH}$ and Machiavellianism but high on OI being the most likely to commit UPB. However, if the employees' OI was low, $\mathrm{HH}$ and Machiavellianism did not make them more likely engage in UPB. Thus, OI was shown to be an important factor in determining whether employees engaged in UPB or not, and that an employee's propensity to engage in unethical acts strengthened this relationship.

In a follow-up study, Effelsberg and Solga (2013) examined whether a transformational leader's own OI made them more likely to engage in UPB, when placed with an ethical dilemma. Specifically, the ethical dilemmas the managers were presented with came from Umphress et al.'s (2010) six-item UPB scale in which participants are asked to choose whether they would engage in acts such as lying, to serve their company. Second, the authors examined how the manager's self-reported OI and willingness to commit UPB influenced follower's perceptions of their transformational leadership. They predicted that leader OI and UPB would be positively related to follower perceptions of transformational leadership. The results of this study, however, were mixed. The authors found support for their hypothesized relation between leader OI and intention to commit UPB $(r=.21)$ but failed to find a significant association between leader UPB and perceptions of transformational leadership. Despite the lack of a relationship between 
manager UPB and transformation leadership perceptions, the relation between manager OI and UPB provided support to Umphress and Bingham's (2011) model, which asserted that employees who identified strongly with their organization would be more likely to commit UPB.

Another leadership style that was investigated by Miao, Newman, and Xu (2013) was ethical leadership, which referred to a leader's tendency to model as well as reinforce appropriate norms regarding ethical conduct at the workplace. Additionally, they investigated the moderating role of subordinate's OI, hypothesizing that it would make the relationship between ethical leadership and subordinate UPB stronger. The authors argued that the behavioral cues and the reward/punishment contingencies given off by the supervisor are important because subordinates refer to them when determining which behaviors are unacceptable at their workplace. The authors postulated there would be a curvilinear relationship that existed between ethical leadership and subordinate UPB and whether that relationship was moderated by the subordinate's OI. The authors predicted that subordinates would engage in the highest levels of UPB when ethical leadership was moderate versus when it was high or when it was low. They reasoned that employees would engage in more UPB when ethical leadership was moderate than when it was low because they tend to have higher quality exchange-based relationships with the supervisor and higher levels of OI. Moreover, the authors hypothesized that employees experiencing high levels of ethical leadership would be less likely (compared to moderate levels) to engage in UPB because the manager would not send conflicting cues regarding what behaviors are appropriate versus inappropriate while at work. Finally, they authors predicted that subordinates with unethical leaders would be less likely to engage in UPB's because of unethical leadership's negative relationship with OI. 
The authors found support for their predicted curvilinear relationship between ethical leadership and UPB, which showed that UPB was highest for supervisors with moderate levels of ethical leadership and lower for those with low and high levels of ethical leadership. Moreover, the results suggested that this relationship was stronger for individuals who had high levels of OI than those with lower levels, supporting the author's second hypothesis. In all, these results emphasized the need for supervisors to send clear and consistent signals to their subordinates regarding ethicality.

Additional work on the relation between leadership style and UPB can be found in Graham, Ziegert, and Capitano (2013), who investigated the role that transformational and transactional leadership styles had on subordinate's intentions to commit UPB. They predicted that messages delivered by transformational leaders would be more likely to lead to subordinate UPB than those from transactional leaders, due to transformational leadership's positive association with OI. In addition to leadership style, the manner in which these leaders framed their messages was also manipulated in the study. Specifically, the moderating role that loss versus gain framing had on the relation between leadership style and UPB was examined. Loss framing refers to when leaders emphasize the level of threats to the company and the negative outcomes associated with that threat, while gain framing emphasizes the likelihood of success and focuses on positive outcomes. The authors predicted that when gain framing was used, the effect of leadership style would be non-significant and when loss framing was used, the effect of leadership style would be significant. Moreover, the authors asserted that when loss language was used, participants with transformational leaders would be more likely than those with transactional leaders to engage in UPB. 
The authors employed a $2 \times 2$ scenario-based experimental design to investigate these causal relationships, as well as to examine the moderating role of participant's promotion focus on the interaction between leadership style and framing. Promotion focus is an individual difference variable that refers to the extent to which individuals scan their social environment for information that may influence their success, such as those associated with career advancement. Furthermore, individuals who are high on the promotion focus trait have been shown to be motivated by positive role models (Lockwood et al., 2002). Therefore, promotion focus should enhance the interaction effect between framing and leadership style have on participants' UPB. The results supported both of the authors' hypothesized interactions. Specifically, the results showed that when transformational leaders used loss framing, they motivated their employees to commit the most UPB. However, when gain framing was used, there were no significant differences between leadership styles. For the 3-way interaction, the results suggested that when individuals with high promotion focus had a transformational leader who framed the situation in terms of losses, that they would engage in the highest levels of UPB. In contrast, high promotion focused individuals, who had transactional leaders who presented the situation in terms of losses, were the least likely to commit UPB. Overall, these findings suggested that transformational leaders may unintentionally make some of their employees more likely to engage in unethical acts in their attempts to motivate them.

\section{Relation between UPB and CWB}

UPB and CWB are similar in many ways. For instance, UPB and CWB's operational definitions share many characteristics. For example, they both encompass volitional acts that would be considered to be unethical, due to the harm they do to the organization and its members, as well as its external stakeholders. Moreover, these behaviors violate key societal 
values, laws, and norms (Donaldson \& Dunfee, 1994). In addition to being considered unethical, these constructs explain overlapping sets of behaviors, such as lying and theft. However, the main difference that can be highlighted in the definitions of UPB and CWB are the intentions that underlie the act.

In the case of CWB, the intent is generally to harm the organization, its members, or both. However, it is important to note that in Bennett and Robinson's (2000) model, any behavior that causes harm to the organization, regardless of one's intentions, is considered to be CWB. Umphress and Bingham (2011) argued that what separated UPB from other related constructs is that it is primarily motivated by one's desire to help the organization. Despite this theoretical distinction though, one can argue whether an employee truly engages in any act without considering their own interests, along with that of the organization's.

Empirically, this underlying assumption in Umphress and Bingham's (2011) model was investigated in a study by Lee et al. (2017), who found that status striving mediated the relation between psychological entitlement and UPB. This finding suggests that individuals may engage in UPB to secure interpersonal influence and power for themselves. Furthermore, UPB and CWB were found to be positively correlated to each other $(r=.22)$. In addition to this finding, Castille et al. (2016) found that employees who were high in Machiavellianism, were more likely to engage in UPB. Previous literature on Machiavellianism has shown that these individuals are primarily motivated by self-serving interests, even at the expense of others and their organizations (Daling et al., 2009). This perspective was reflected in Castille et al., where they asserted that Machiavellianism's relation to UPB is likely due to the individual's own interests aligning with the organizations. Moreover, the facet of Machiavellianism that was found to explain the most variance in UPB, was amoral manipulation. According to Castille et al., this 
facet has been shown to be closely aligned with the assertion that Machiavellians are rational opportunists. Thus, it seems likely that rather than being motivated to "help" the organization, these individuals were primarily motivated by the rewards they may receive.

Another important similarity between CWB and UPB can be found in the consequences they have for organizations. An important component of Bennett and Robinson's (2000) conceptualization of CWB is that it results in harm to the company and/or its members. In contrast, Umphress and Bingham (2011) argue that UPB is differentiated from constructs, such as CWB, because it benefits the company. However, UPB may inevitably lead to negative consequences for the organization as well. According to Umphress and Bingham, "although employees may aim to help, the end result of their actions may be inconsistent with their intentions" (Umphress \& Bingham, 2011,pg. 623). Therefore, it seems that these two constructs may ultimately lead to aversive consequences for the company.

As has been noted in various reviews of $\mathrm{CWB}$, the literature has developed in a fractured way, due to the lack of an accepted organizing theoretical framework, which has resulted in a proliferation of constructs. Even though constructs such as incivility, anti-social behavior, and CWB may maintain subtle differences, they ultimately explain and overlapping set of behaviors that may be subsumed by CWB. Moreover, these constructs tend to be positively correlated to each other (Bowling \& Gruys, 2010; Griffin \& Lopez, 2005, Marcus et al., 2013). However, according to Griffen and Lopez (2005), one of the ways we can assess the discriminant validity of these various constructs is by investigating whether they have similar sets of situational and person antecedents.

The literature in UPB has shown some support for UPB and CWB sharing similar traitantecedents. For instance, Machiavellianism has been found to be related to UPB (Castille, 
Buckner, \& Thoroughgood, 2016) and CWB (Greenbaum et al., 2017). Moreover, psychological entitlement was found in Lee et al. (2017) to be related to UPB and CWB. Therefore, due to the results of these previous findings, as well as the conceptual similarities between the UPB and CWB constructs, I predict that UPB and CWB will be positively correlated to each other.

\section{Hypothesis 1: CWB and UPB will be positively correlated}

\section{Conscientiousness and Unethical Pro-Organizational Behavior}

As was discussed earlier, conscientiousness has been shown to be a robust predictor of CWB, a construct that encompasses a multitude of deviant and unethical acts (Berry, Ones, \& Sackett, 2007; Salgado, 2002). In contrast, conscientiousness has been shown to be positively associated with incumbent job performance (Barrick, Mount, \& Judge, 2001). Additionally, conscientiousness has been found to be the primary construct that workplace integrity tests tap into - tests which are designed to measure an applicant's propensity to engage in dishonest behaviors at work, such as theft (Marcus, Lee, \& Ashton, 2007; Bakker, Demerouti, \& ten Brummelhuis, 2012; Salgado J. F., 1997). Empirical work examining conscientiousness' link to ethical behaviors has shown that individuals who are high on conscientiousness tend to pay attention to and abide by ethical principles, and approach their work with integrity (Colquitt et al., 2006; J. Hogan \& Ones, 1997; Horn, Nelson, \& Brannick, 2004; McFerran, Aquino, \& Duffy, 2010, Mc Ferran et al., 2010; Moon, 2001; Murphy \& Lee, 1994). In contrast, studies have found that those who are low in conscientiousness are less concerned with moral obligations and less likely to act on their conscience (Colquitt et al., 2006; Costa \& McCrae, 1992; Goldberg, 1992; R. Hogan \& Blake, 1996; McFerran et al., 2010; Moon, 2001).

Conscientiousness' linkage to dishonest behaviors may be explained by Gottfredson and Hirchi's (1990) theory of self-control. Gottfredson and Hirchi were criminologists, who aimed to 
identify a link between what they referred to as the "versatility and stability of crime." This phrase described the fact that criminal behaviors and their analogous, deviant acts tend to be positively correlated to one another over long periods of time. After extensive study, Gottfredson and Hirchi suggested that those who committed these deviant acts could be characterized by a general lack of planning and consideration of the long-term consequences of their behavior, instead preferring acts that provided short-term gains. Their explanation for this phenomenon, was a latent personality trait, self-control. They defined it as the tendency for individuals to avoid behaviors whose momentary advantages were outweighed by their long-term costs. Conscientiousness captures this relation between self-control and unethical behaviors because at higher levels it characterizes individuals who are high in self-discipline and self-control and are also more likely to follow workplace rules and social norms governing behavior.

Empirical support for self-control's relation to unethical behavior has been found in a number of studies across numerous disciplines (Gino, Schweitzer, Mead, \& Ariely, 2011; Marcus \& Schuler, 2004; Blickle, Schlegel, Fassbender, \& Klein, 2006), including two metaanalyses (Pratt \& Cullen, 2000; Vazsonyi, Mikuska, \& Kelly, 2017). Pratt and Cullen (2000) conducted the first meta-analysis aimed at examining Hirschi's and Gottfredson's (1990) selfcontrol theory. Their meta-analysis revealed effect sizes of 0.20 , suggesting that self-control was one of the most robust correlates of crime. Moreover, it was found that varying operationalization's of self-control and different sample characteristics did not attenuate this relationship. Thus, this study provided strong empirical support for self-controls link to crime and its analogous deviant behaviors.

Vazsonyi, Mikuska, and Kelly (2017) built on Pratt and Cullen's findings by incorporating a much larger sample of cross-sectional and longitudinal studies. The studies that 
were included in the most recent meta-analysis also contained more culturally diverse samples, which the previous meta-analytic study by Pratt and Cullen lacked. Lastly, Vazsonyi et al. also employed more sophisticated statistical analyses, that included moderated multiple regression, methods that assessed publication bias such as funnel plot inspection, and Begg and Mazumdar's Rank Correlation Test (1994). The results of their meta-analysis, like Pratt and Cullen's, provided considerable support to Hirchi and Gottfredson's (1990) self-control theory. Their main finding was that self-control consistently predicted criminal and deviant behaviors, reporting a weighted random effects mean correlation coefficient of 0.415 . Further analysis of this relationship showed that the strongest correlation was between low self-control and general deviance $(\mathrm{r}=0.56)$.

Given this collection of findings demonstrating the relation between one's ability to selfregulate and unethical behaviors, I predict that conscientiousness will be negatively related to UPB. Those who are high on C should be more likely to consider the long-term consequences of acts of UPB. Additionally, conscientious employees will be more likely to follow the rules and norms governing behavior at work. One of the boundary conditions of UPB is that it encapsulates behaviors that fall outside traditional job roles, as outlined by the company and are done under the employee's own free will. Therefore, they should be less likely to engage in behaviors that are not part of their official job descriptions and have not been asked of them by their supervisors. Second, I hypothesize that, in accordance with Hirchi's and Gottfredson's (1990) general theory of crime, self-control will mediate the relationship between C and UPB.

Hypothesis 2: Conscientiousness will be negatively related to participant unethical proorganizational behavior. 
Hypothesis 3: Self-control will mediate the relationship between conscientiousness and unethical pro-organizational behavior.

\section{Honesty-Humility and Unethical Pro-Organizational Behavior}

As was discussed earlier, $\mathrm{HH}$ reflects one's propensity to deceive others and break rules for self-gain (Ashton et al., 2004; Zettler and Hillbig, 2010). HH's validity as a legitimate factor under the HEXACO model of personality has been demonstrated across numerous empirical studies and cannot merely be subsumed under the Big Five's agreeableness factor (Ashton et al., 2004; Ashton, Lee, \& de Vries, 2014). Moreover, HH has been shown to be a strong trait predictor of CWB and its analogous acts (Lee, Ashton, and Shin, 2005; Lee, Ashton, and de Vries, 2005; Ashton \& Lee, 2008b; Zettler \& Hillbig, 2010). However, there have been no studies to date on whether HH is predictive of a related yet, distinct construct in UPB. The closest example of a study investigating the relation between one's propensity to engage in unethical acts and UPB, can be found in Castille et al. (2016), who found a positive relationship between Machiavellianism and UPB $(r=.40)$.

Machiavellianism, along with psychoticism, and narcissism, are members of the Dark Triad. Together, these traits capture one's propensity to engage in a variety of dishonest and selfpromoting behaviors (O'Boyle, Jr. et al. 2012). In a series of studies by Ashton and Lee (2009), they examined the relation between the factors of the Dark Triad with the HEXACO model's HH factor and found that $\mathrm{HH}$ accounted for the same variance as that of the Dark Triad. Therefore, the results of these studies clearly demonstrated that these factors are highly related to one another and are essentially trying to explain the same overlapping set of behaviors. Thus, Castille et al.'s (2016) finding in conjunction with the results of Ashton and Lee's studies, seem to insinuate that $\mathrm{HH}$ (due to its shared variance with Machiavellianism), is likely to be related to 
UPB as well. However, despite the robustness of the empirical relationships that have been established among the Dark Triad, and other factors (C, HH, agreeableness), it is not wellunderstood why these traits are related to deviant behaviors, such as CWB. A theory proposed by Tett and Burnett (2003) though, called Trait Activation Theory (TAT), may help bridge this gap in our understanding of these relationships.

The central tenant of TAT is that particular situations will motivate the expression of certain traits through the employees' perception and interpretation of cues from their organizational environment (Tett \& Burnett, 2003). This process was referred to by Tett and Burnett (2003) as "trait activation," which states that personality traits are expressed as responses to trait relevant cues. Trait relevant cues come from multiple sources and levels within an organization. At the lowest level, trait-relevant cues may stem from the nature of the employee's work, and at its highest levels come from the organizational culture or climate. However, before these trait-relevant cues can be acted upon, the employee must first find themselves in a situation in which there is an opportunity to engage in trait-relevant behavior. For instance, if an outgoing employee is placed in a work context where they do not have many opportunities to engage with customers or other employees, their outgoingness will never be given a chance to be expressed.

In the context of UPB, HH is mostly like to be expressed when an employee is presented with a situation in which there is an opportunity to engage in dishonest behaviors, such as lying to a customer about the quality of their company's products. Therefore, in accordance with past studies that have established empirical connections between $\mathrm{HH}$ and unethical behaviors in organizations, as well as TAT, I predict that HH will be negatively related to UPB.

Hypothesis 4: Honesty-Humility will be negatively related to unethical proorganizational behavior. 


\section{Bottom-line Mentality and Unethical Pro-Organizational Behavior}

In addition to the, "fertile theoretical ground for considering how personality theory might complement...the study of UPB (page 9, Castille, Buckner, \& Thoroughgood, 2016)," there have also been calls in the UPB literature to identify potential moderators of UPB (Kish \& Gephart et al. 2010), such as bottom line mentality (BLM).

The BLM construct was first proposed by Greenbaum, Mawritz, and Eissa (2012). In their study, they investigated the role that supervisor BLM had on the focal employee's BLM and subsequent social undermining behavior. In their study, BLM was conceptualized as the "tunnel vision" that supervisors would develop when they prioritized one organizational objective over all of the rest. In turn, the supervisor's employees would pursue this goal at the costs of all the others. This tunnel vision is an issue, because in the environments that organizations exist, they must consider not only the concerns of their investors and generating profit but also how their actions may affect their customers. Moreover, in the employee's pursuit of the bottom-line outcome, they may attempt to cut corners, which may be reflected in the quality of their work. For instance, if a worker is paid by the number of units they produce, they may sacrifice quality for quantity. Furthermore, the employee may engage in different kinds of unethical acts to achieve the bottom-line.

In the employees' attempt to achieve the bottom-line outcome, they may engage in a number of unethical behaviors, such as lying, cheating, or withholding information that may result in harm to external stakeholders. Furthermore, their behaviors may lead to detrimental outcomes for those they work with as well. For instance, in Greenbaum et al.'s (2012) study, they looked at a form of sabotage called social undermining and its relation to supervisor and employee BLM. They asserted that in the employees' pursuit of the goal, they may start to 
compete with other coworkers, seeing the goal's attainment as a game they must win, and others must lose. This competitiveness along with the incumbent's BLM, may motivate them to engage in behaviors that attempt to thwart their coworkers. Examples of the forms that social undermining may take, included providing coworkers with incorrect information, intentionally slowing them down, or trying to make them look bad.

The authors theorized that the supervisor's focus on bottom-line outcomes, such as sales, may inadvertently lead to subordinate social undermining. They drew on social-cognitive theory to suggest that the supervisor serves as a salient role model that subordinates look to for cues regarding the behaviors that the organization values and rewards. Thus, through observational learning and modeling, the subordinate will likely adopt similar attitudes. Evidence for this topdown approach, can be found in trickle-down models that have linked the attitudes and behaviors of high-level officials in the organization to subordinate's attitudes and behaviors at lower levels (Bass, Waldman, Avolio, \& Bebb, 1987; Mayer, Kuenzi, Greenbaum, Bardes, \& Salvador, 2009).

The final components of Greenbaum et al.'s (2012) model focused on trait moderators of the employee BLM and social undermining relationship. Their rationale was that although an employee may find themselves in an organization that values only the achievement of the bottom-line through any means necessary, it does not mean that they will necessarily engage in unethical acts to attain it, hypothesizing that employees who were high in conscientiousness and core self-evaluations (CSE), would be less likely to engage in social undermining.

The results of Greenbaum et al.'s (2012) study supported their moderated-mediation model. Their findings suggested that supervisor BLM was mediated through employee BLM, and that this relation was moderated by the employee's level of conscientiousness and CSE. Specifically, 
they found that at higher levels of conscientiousness and CSE, that the indirect effect of supervisor BLM through employee BLM on social undermining was weaker than at lower levels. All-together, these findings provided support for top-down models by demonstrating how the organization and/or supervisor's endorsement of norms regarding BLM may inadvertently lead to subordinate's adopting and acting upon these similar attitudes.

In the UPB literature, there has only been one study that has examined BLM's relation to UPB. In Castille et al.'s (2016) study, they investigated whether bottom-line mentality climate perceptions (BLMCP) or “an employee's perception that coworkers pursue organizational goals and interests at the expense of competing priorities, such as those specified by ethical guidelines and standards of conduct" (page 4, Castille, Buckner, and Thoroughgood, 2016) strengthened the relation between trait Machiavellianism and UPB such that those who were high in Machiavellianism would be more likely to engage in UPB when BLMCP was high than those who were low on trait Machiavellianism. Their results found Machiavellianism to be positively related to UPB, however, this relation was not strengthened by BLMCP. The authors hypothesized this null finding may have been due to Machiavellian employees already being prone to engaging in acts that would promote their own or their company's interests, that there was little room for situational interaction to occur. In other words, Machiavellian employees are likely to indicate that they would be more willing commit high levels of UPB regardless of what environment they are in. However, the authors hypothesized that if they had measured actual UPB behaviors, rather than willingness to commit UPB, the employee's perceptions of BLM at their workplace may have had more of an effect. Thus, the current study will address this particular limitation by using a revised version of Umphress et al.'s (2010) scenario-based measure in which UPBs that employees have actually engaged in while at work will be assessed. 
The current study will investigate the moderating effect of BLM on the relation between traits and UPB, due to the limitations that existed in past studies (Castille, Buckner, and Thoroughgood, 2016) as well as prior studies, that found a positive relation between employee BLM and another analogous deviant act (Greenbaum, Mawritz, and Eissa, 2012). As was demonstrated in Greenbaum et al.'s (2012) study, if an employee were to perceive that individuals at their company valued the bottom-line, they would likely adopt a similar attitude. In turn, the employee may, in their attempt to achieve this valued outcome, engage in behaviors that harm external stakeholders. However, as Greenbaum et al. showed, individual differences may reduce the likelihood that an employee, who finds themselves in a company who values the bottom-line, might engage in UPB's.

Drawing on these findings, as well as TAT, I hypothesize that an employee's perceptions of an organization's BLM will moderate the relation between honesty-humility and UPB and self-control and UPB. Specifically, I predict that the negative relation between self-control and UPB and honesty-humility and UPB will be stronger when perceptions of BLM are high than when they are low.

Hypothesis 5a: Employee perceptions of organizational bottom-line mentality will moderate the relationship between honesty-humility and UPB such that those who are low on honesty-humility will be more likely to engage in UPB when they are placed in an environment they perceive to value the bottom-line.

Hypothesis 5b: Employee perceptions of organizational bottom-line mentality will moderate the relationship between self-control and UPB such that those who are low on self-control will be more likely to engage in UPB when they are placed in an environment they perceive to value the bottom-line. 


\section{CHAPTER III: RESEARCH DESIGN}

\section{Method}

\section{Participants}

The sample that was used for the study, was collected through Amazon's Mechanical Turk Program (Mturk). Research on Mturk has shown that it is a viable tool for collecting data, allowing researchers to gather information from diverse samples of individuals (Behrend et al. 2011). The total sample consisted of 630 U.S. workers ( $54.9 \%$ female, $45.1 \%$ male), and the average age was 39.08 years. Participants indicated they had worked, on average, 39.67 hours per week and that $44.3 \%$ were currently working in managerial positions. Participants had been filtered by the number of hours they had worked per week (at least 20 hours per week over a period of 3 months), to ensure that they had received adequate opportunities to engage in UPB. The sample was not filtered based on occupation, due to constraints on funding and to ensure there was enough statistical power to detect an anticipated small effect size. Thus, the occupations and industries that participants worked in were quite diverse, with participants working across 13 different industries. The most common industries that participants worked in were service, business and sales, and science and technology. Together, these industries comprised over $53 \%$ of the sample.

The sample size was determined based on the results of a power analysis, which had indicated that for an anticipated small effect size, a sample of approximately 620 participants was needed (Murphy, Myors, and Wolach, 2014). This conservative estimate was used based on effect sizes that had been found in previous studies on UPB, as well as to ensure that the analyses would have adequate statistical power (Castille, Buckner, \& Thoroughgood, 2016; Effelsberg, Solga, \& Gurt, 2014; Effelsberg \& Solga, 2015; Umphress, Mitchell, \& Bingham, 2010). 


\section{Measures}

\section{Unethical Pro-Organizational Behavior}

In the current study, Umphress et al.'s (2010) six-item measure of UPB was used. Example items included "because it was needed, I have concealed information from the public that could be damaging to my organization" and "because it was needed, I have exaggerated the truth about my company's products or services to customers and clients." Each of the items were rated on a seven-point, Likert-type scale with scores ranging from 1 (strongly disagree) to 7 (strongly agree). Evidence regarding the validity and reliability of Umphress et al.'s original UPB measure had been gathered through the use of exploratory (EFA) and confirmatory factor analyses (CFA). The results of their exploratory factor analysis revealed that all of the items, with the exception of one, loaded adequately onto a single latent factor (all item factor loadings exceeded 0.5 ), that accounted for $66.9 \%$ of the variance. Additionally, the measure had favorable reliability, reporting a coefficient alpha of 0.89

To assess the measure's discriminant validity, the authors ran a CFA in which they compared it to 3 other measures of ethical and extra-role behaviors. The results of the CFA suggested that the four-factor model fit the data best, recording a CFI of 0.96 and RMSEA of 0.07. The UPB measure also reported a Cronbach alpha of .90 in this particular analysis. Moreover, they found that UPB was negatively related to in-role behavior $(r=-.12)$ but was not related to organizational citizenship behavior directed toward the organization, nor was it related to organizational citizenship behavior directed toward individuals. Lastly, the authors tested the discriminant validity of their measure against Bennett and Robinson's (2000) measure of CWB. The results of their CFA suggested that the hypothesized three factor model provided the best fit to the data $(\chi 2(272)=1,257, \mathrm{CFI}=0.97, \mathrm{RMSEA}=0.10)$, and $\mathrm{UPB}$ was positively related to 
both organizational $(r=.4)$ and interpersonal deviance $(r=.41)$. Lastly, the UPB measure reported a Cronbach alpha estimate of .91 .

Additional examinations of the scale's internal consistency reliability can be found across six studies examining UPB; the average Cronbach's alpha that was reported in these studies was 0.84 (Miao et al., 2013; Graham, Ziegert, and Capitano, 2015; Kong, 2016; Castille, Buckner, and Thoroughgood, 2016; Effelsberg \& Solga, 2015; Lee et al., 2015). Despite this high reliability estimate though, there has been evidence that has suggested dropping one of the items from the scale. In a factor analysis conducted by Effelsberg, Solga, and Gurt (2014), the results suggested that reliability could be increased if one of the original items was dropped ("If my organization needed me to, I would give a good recommendation on the behalf of an incompetent employee in the hope that the person will become another organization's problem instead of my own.”). The resulting coefficient alpha estimates across their two studies were 0.81 and 0.77 , respectively. This finding was replicated in Wang et al. (2018), who also found that Umphress et al.'s (2010) UPB scale had better reliability without the item, finding a Cronbach's alpha estimate of 0.86 when the item was removed.

However, in the current study, a modified version of Umphress et al.'s (2010) scenariobased UPB scale was used. In this modified version of the scale, participants' actual UPBs were measured. For example, one item was rewritten to, "because it was needed, I have concealed information from the public that could be damaging to my organization." The rest of the rewritten items can be found in Appendix E. The revised scale reported a Cronbach's alpha estimate of 0.93 , which was higher than the average of 0.84 , that had been reported previously (Miao et al., 2013; Graham, Ziegert, and Capitano, 2015; Kong, 2016; Castille, Buckner, \& Thoroughgood, 2015; Effelsberg \& Solga, 2015; Lee et al., 2015). 


\section{Counterproductive Work Behavior}

The current study used Bennett and Robinson's (2000) measure of workplace deviance to measure CWB. The measure consists of 12 items that are aimed at assessing different types of organizational-directed deviance (CWBO) and seven items that assess different forms of interpersonal-targeted deviance (CWBI). Each of the measure's items were ranked on a 5-point, Likert-type scale, with scores ranging from 1 (strongly disagree) to 5 (strongly agree). A sample interpersonal deviance item would be, "said something hurtful to someone at work," and a sample organizational deviance item would be, "taken property from work without permission." Bennett and Robinson conducted a CFA to test their hypothesized two-factor structure, using maximum likelihood estimation. The results of the CFA supported this model, $\chi 2(251, \mathrm{~N}=143)$ $=198.37 \mathrm{p}<.001, \mathrm{RMSR}=.05, \mathrm{GFI}=.87, \mathrm{CFI}=0.90, \mathrm{NFI}=.88)$. Their organizational and interpersonal sub-scales also had good reliability, reporting Cronbach alpha estimates of 0.81 and 0.78 , respectively.

The reliability of Bennett and Robinson's (2000) CWBO and CWBI subscales were further examined in Dalal's (2005) meta-analysis, who reported Cronbach alphas of 0.77 and 0.68 for CWBO and CWBI, respectively. In a later meta-analysis, conducted by Berry, Ones, and Sackett (2007), they reported higher Cronbach alpha estimates of 0.82 (CWBO) and 0.84 (CWBI) for each of the subscales. Thus, the average Cronbach alphas reported across these two meta-analyses and Bennett and Robinson's (2000) study, were 0.8 (CWBO) and 0.77 (CWBI). In the current study, Bennett and Robinson's interpersonal CWB sub-scale recorded a Cronbach alpha estimate of 0.91 and recorded an estimate of 0.92 for their organizational sub-scale. 


\section{Bottom-line Mentality}

To measure BLM, I used a slightly revised version of Greenbaum et al.'s (2012) fouritem measure of their employee and supervisor BLM measures, that was employed in Castille et al.'s (2016) study, to reflect an employee's perceptions of their coworker's BLM, which they referred to as bottom-line mentality climate perception (BLMCP). To ensure that the items reflected the employee's perception of their coworker's BLM, the authors reworded the original items by replacing the "I" with "people here." Sample items were, "people here are solely concerned with meeting the bottom-line" or "people here treat the bottom-line as more important than anything else." The internal consistency reported was high, with their revised BLM scale having a Cronbach's alpha of 0.93, compared to Greenbaum et al. reported alpha of 0.86 for their employee BLM measure and 0.92 for their supervisor BLM scale. Across all of the versions of Greenbaum et al.'s original BLM scale, the items were ranked on a 7-point, Likert-type scale (1 $=$ strongly disagree to $7=$ strongly agree).

In a series of scale development and validation studies conducted by Greenbaum et al. (2012), they examined the psychometric properties of their supervisor and employee BLM scales across five samples. In their first sample, they conducted an exploratory factor analysis (EFA) on their four BLM items and found that they loaded onto a single latent factor, accounting for $79 \%$ of the variance. In sample two, they followed-up with a CFA that used maximum-likelihood estimation, which showed good fit, despite the high RMSEA $[\chi 2(2, \mathrm{~N}=60)=3.96$, RMSEA $=$ $.13, \mathrm{CFI}=.99, \mathrm{GFI}=.97, \mathrm{SRMR}=.02]$. The authors argued that the high RMSEA should not be problematic, due to the fit measure's tendency to be inaccurate when working with small sample sizes. In their third sample, they examined a BLM scale aimed at measuring the supervisor's assessment of their own BLM, using EFA. The results showed that the items converged onto a 
single factor that explained 79\% of the variance and reported a Cronbach's alpha of .90. In sample four, using this same supervisor BLM scale, they conducted a CFA that had adequate fit, $[\chi 2(2, \mathrm{~N}=275)=13.86, \mathrm{p}<.001, \mathrm{RMSEA}=.15, \mathrm{CFI}=.98, \mathrm{NNFI}=.94, \mathrm{GFI}=.98, \mathrm{SRMR}=$ .03. The scores in this sample had a Cronbach's alpha of 0.88. In addition to the CFA, the authors also examined the BLM construct's convergent and discriminant validity, by investigating how it related to measures of goal difficulty and goal-contingent reward. They found that BLM was positively correlated with goal difficulty $(r=.25)$ and goal-contingent reward $(\mathrm{r}=.14)$. Next, they examined BLM's discriminant validity against goal difficulty, using chi square difference tests between a one factor and three factor model. Their findings suggested that each of the items loaded onto their respective factors, forming a three-factor model. In their fifth and final sample, the authors performed a CFA on the employee BLM items, using maximum likelihood estimation, $[\chi 2(2, \mathrm{~N}=273)=10.89, \mathrm{p}<.001, \mathrm{RMSEA}=.13, \mathrm{CFI}=.99$, NNFI $=.97, \mathrm{GFI}=.98, \mathrm{SRMR}=.02$. The Cronbach's alpha for this sample was 0.85. In the current study, Greenbaum et al.'s BLM scale reported a Cronbach Alpha reliability estimate of 0.92. Overall, these findings suggest that Greenbaum et al.'s scale seems to be a reliable and valid measure for assessing supervisor and employee BLM.

\section{HEXACO-PI-R}

To measure participant conscientiousness and honesty-humility, I used items from Ashton and Lee's (2009) 60-item HEXACO-PI-R. In this version of the HEXACO-PI-R, each trait and its corresponding sub-scales contains 10 items, that are ranked on a 5-point, Likert-type scale $(1=$ strongly disagree; $5=$ strongly agree $)$. Specifically, conscientiousness is composed of four sub-scales that measure organization, diligence, perfectionism, and prudence. Sample items include, "I plan ahead and organize things to avoid scrambling at the last minute" and "I often 
push myself very hard when trying to achieve a goal." Honesty-humility also consists of four sub-scales that measure sincerity, fairness, greed-avoidance, and modesty. Sample items from its sub-scales include, "If I knew that I could never get caught, I would be willing to steal a million dollars" and "I would never accept a bribe, even if it were very large." The rest of the HH and C items can be found in the appendix.

When Ashton and Lee (2009) were constructing the scale, they chose items from their 100-item HEXACO-PI-R measure, based on their respective factor loadings. The items that had high loadings and low secondary loadings were included in the 60 -item HEXACO-PI-R. The authors examined the psychometric properties of the scale across a college sample $(\mathrm{N}=936)$ and a sample of community adults $(\mathrm{N}=734)$. The inter-item correlation for the $\mathrm{HH}$ and $\mathrm{C}$ items ranged were .27 and .26 , respectively, in the student sample and 0.23 and 0.24 , in the community adult sample. The Cronbach alpha estimates for $\mathrm{HH}$ and $\mathrm{C}$ were .79 and .78 , respectively, in the student sample and .74 and .76 in the community adult sample. The items' underlying factor structure was analyzed using principal axis extraction with varimax rotation.

The results of the principal axis extraction showed that the first six common factors accounted for $37.4 \%$ of the item variance in the college sample and $29.1 \%$ of the item variance in the community adult sample. The varimax rotation revealed that all of the items loaded on to their respective factors. Additionally, the factor analysis that was conducted each of the 24 underlying facets, suggested a six-factor structure.

All together, these results suggest that the 60-item HEXACO-PI-R suffers a modest loss in reliability compared its 100-item counterpart. Thus, the authors recommend its use for settings in which time constraints is a factor. However, they would not recommend pulling items from its facet scales, due to each facet scale containing only 2-3 items. Therefore, the measure's use in 
the current study was appropriate, given that the data was collected through an online self-report survey. In the current study, the scales' internal consistency reliabilities revealed a Cronbach Alpha estimates of 0.78 for the honesty-humility sub-scale and an estimate of 0.8 for the conscientiousness sub-scale.

\section{Brief Self-Control Scale}

The brief (13-item) self-control scale was derived from Tangney, Baumeister, and Boone's (2004) 32-item self-control scale. In their study, self-control was conceptualized as the, “ability to override or change one's inner responses, as well as to interrupt undesired behavioral tendencies and refrain from acting on them (page. 274)." The original item pool they developed for the scale primarily focused on one's ability to control their own thoughts, emotions, and impulses, regulate their performance, and break undesirable habits. Each of the items was rated on a 5-point, Likert-type scale ranging from 1 (not at all like me) to 5 (very much like me). The Cronbach's alpha estimates for the 32-item self-control scale and the brief self-control scale were 0.89 and 0.84 , respectively. However, in the current study, the brief self-control scale recorded a Cronbach Alpha estimate of 0.88 , which was slightly higher than the estimate reported by Tangney et al. The test-retest reliabilities for each of the scales was conducted by having participants take each of the assessments a second time, three weeks later. The test-retest reliability for the 32 -item scale was 0.89 and was 0.87 for the brief self-control scale. In addition to the high reliability estimates, the scales also showed a high degree of convergent validity, recording a correlation coefficient of 0.93 . Further support for the scale's validity can be found in the strong relations that were observed between self-control and the various outcomes that they were hypothesized to be related to. In Tangney et al.'s study, both of their self-control 
scales were found to have significant positive correlations to academic and task achievement, impulse control, psychological adjustment, and quality of interpersonal relationships.

In a meta-analysis conducted by Ridder et al. (2012), they examined self-control's effect sizes, across three different measures of self-control. For Tangney et al.'s self-control scale, the authors were able to examine effect sizes from over 50 studies. Out of those studies, they found that $61 \%$ had used Tangney et al.'s brief self-control scale and $20 \%$ had used their 32 -item self-

control scale. All-together, a small to medium effect size was found across all of the studies that had used the self-control scale $(\rho=0.26, \mathrm{p}<.001)$.

\section{Procedure}

The study's measures were completed online through Amazon's Mturk The participants received $\$ 0.30$ for their participation in the study. Due to the nature of the variables being studied, a message assuring participant anonymity was presented before the survey was administered, to help control for impression management bias. After agreeing to the consent form, the measures and their individual items were presented randomly to each of the participants as they went through the survey, to control for order effects.

\section{Data Analysis}

Bivariate correlational analyses will be used to examine hypotheses, 1, 2, and 4. To examine hypothesis 3, a simple mediation analysis will be employed. Lastly, a moderated hierarchical regression analysis will be used to examine hypotheses $5 \mathrm{a}$ and $5 \mathrm{~b}$. Specifically, in step 1, C, HH, BLM, and self-control will be entered into the regression model. Then, in step 2, the interaction terms will be entered into the model. 


\section{Results}

\section{Descriptive Statistics}

All descriptives, correlations, and reliability estimates for the study's variables can be found below in Table 1.

Table 1

Means, Standard Deviations, and Correlations of All Study Variables. Cronbach Alpha Estimates Are Displayed in Parenthesis Along the Diagonal.

\begin{tabular}{lcccccccc}
\hline Variable & $M$ & SD & 1 & 2 & 3 & 4 & 5 & 6 \\
\hline 1.Conscientiousness & 38.55 & 6.48 & 0.8 & & & & & \\
2. Self-Control & 43.31 & 9.11 & $0.62^{*}$ & 0.88 & & & & \\
3. HH & 35.1 & 7.38 & $0.39^{*}$ & $0.37^{*}$ & 0.8 & & & \\
4. BLM & 13.52 & 6.39 & $-0.2^{*}$ & $-0.19^{*}$ & $-0.28^{*}$ & 0.92 & & \\
5. CWB & 38.85 & 20.5 & $-0.51^{*}$ & $-0.51^{*}$ & $-0.43^{*}$ & $0.28^{*}$ & 0.95 & \\
6. UPB & 9.41 & 5.3 & $-0.45^{*}$ & $-0.34^{*}$ & $-0.37^{*}$ & $0.35^{*}$ & $0.62^{*}$ & 0.93 \\
\hline
\end{tabular}

Note. Cronbach alpha estimates are in parentheses along the diagonal. $\mathrm{HH}=$ honesty-humility; $\mathrm{BLM}=$ bottom-line mentality; $\mathrm{CWB}=$ counterproductive work behavior; UPB $=$ unethical proorganizational behavior.

$* p<.001$

After screening the data for extreme residuals and influential scores, no individual cases were dropped. Additionally, no individual cases were removed nor filtered out of the study's analyses based on the number of failed attention-check items. This decision was made after conducting a series of analyses in which various cases were filtered out of the analysis based upon their extreme residual scores, degrees of influence, as well as those individuals who had failed the attention-checks. However, after running these various iterations of the analysis, it was found that the decisions regarding the study's hypotheses remained the same. Thus, it was decided that the analyses, which included the entire sample, would be used, given that the same conclusions regarding the study's hypotheses were reached regardless of whether extreme residuals, influential scores, or failed attention-checks were accounted for or not. 


\section{Hypothesis Testing}

\section{Hypothesis 1 - CWB and UPB}

Hypothesis 1 suggested that CWB would be positively related to UPB. The results of the bivariate correlational analysis supported this hypothesis, finding that $\mathrm{CWB}(M=38.85, S D=$ 20.5, $n=622)$ and UPB $(M=9.41, S D=5.3)$ had a strong and positive zero-order correlation, $r$ $=.62, p<.001, n=622$.

\section{Hypothesis 2 - Conscientiousness and UPB}

Hypothesis 2 stated there would be a negative relation between $\mathrm{C}$ and UPB. The results of the bivariate zero-order correlation supported this prediction, finding that $\mathrm{C}(M=38.55, S D=$ 6.48) had a strong negative relation to UPB, $r=-.45, p<.001, n=617$.

\section{Hypothesis 3 - Self-Control and UPB}

A simple mediation analysis was used to examine hypothesis 3 , which suggested that the relation between conscientiousness and UPB would be mediated by self-control. The analysis was conducted using Hayes' (2013) PROCESS macro. Specifically, I used a sample of 582 participants as a population reservoir from which to draw, with replacement, 10,000 samples of $\mathrm{N}=582$. PROCESS computes unstandardized indirect effects for each bootstrapped sample, so the $95 \%$ confidence interval may be determined. The bootstrapped unstandardized indirect effect was $b=0.02$, and the $95 \%$ confidence interval ranged from -.06 to .01 . Thus, hypothesis 2 was not supported, with self-control failing to mediate C's relationship to UPB. Furthermore, it was revealed that when $\mathrm{HH}$, BLM, and C were controlled for, self-control was found to not be related 
to UPB, $\beta=-.03, t(577)=-1.15, p=.25$. The results of the analysis can be found below in Figure 1.

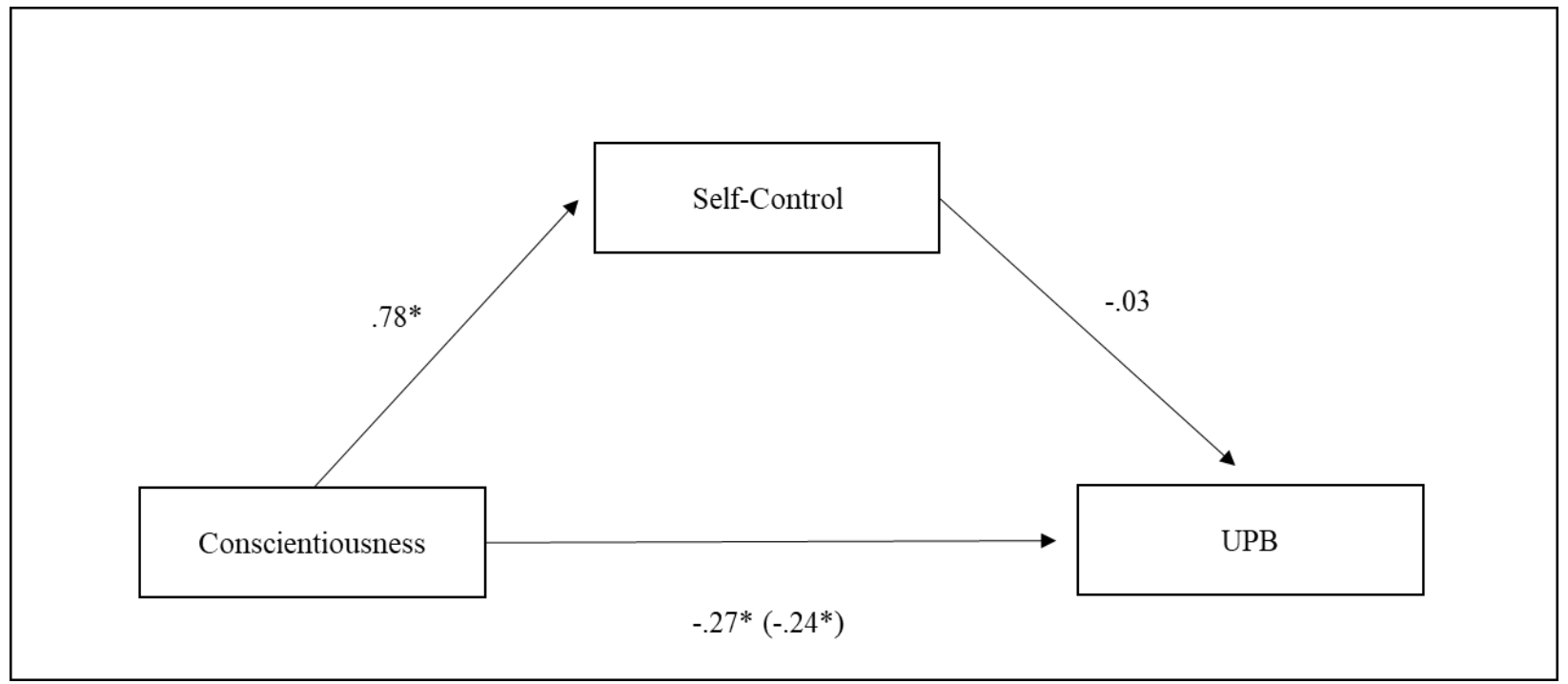

Figure 1. Standardized regression coefficients for the relationship between conscientiousness and UPB as mediated by self-control. The standardized regression coefficient between conscientiousness and UPB, controlling for self-control, is in parentheses.

\section{Hypothesis 4 - Honesty-Humility and UPB}

Hypothesis 4 suggested that HH and UPB would be negatively related. The result of the bivariate zero-order correlation supported this hypothesis, finding that $\mathrm{HH}(M=35.10, S D=$ 7.38) had a strong negative relation to UPB, $r=-.38, p<.001, n=619$. Thus, the zero-order bivariate correlational analyses revealed that all of the relationships between the aforementioned variables were in the expected directions.

\section{Hypothesis 5a - BLM Moderates HH and UPB}

Hypothesis 5a stated that the relation between HH and UPB would be moderated by BLM, such that those individuals with low levels of $\mathrm{HH}$ would be much more likely to commit UPB when BLM was high than those who reported higher levels of HH. The result of this 
analysis can be found below in Table 2 .

Table 2

Hierarchical Regression Analysis Testing the Moderating Effect of Bottom-line Mentality on Honesty-Humility and Unethical Pro-Organizational Behavior

\begin{tabular}{clcccc}
\hline Model & \multicolumn{1}{c}{ Predictor } & $B$ & $S E B$ & $\beta$ & $\Delta R 2$ \\
\hline 1 & Conscientiousness & -0.24 & 0.04 & $-0.3^{*}$ & $.28^{*}$ \\
& Self-control & -0.03 & 0.03 & -0.05 & \\
& HH & -0.13 & 0.03 & $-0.19^{*}$ & \\
& BLM & 0.16 & 0.03 & $0.19^{*}$ & \\
\multirow{2}{*}{2} & & & & & \\
& Conscientiousness & -0.24 & 0.04 & -0.3 & $0.02^{*}$ \\
& Self-control & -0.03 & 0.03 & -0.05 & \\
& HH & -0.14 & 0.03 & -0.21 & \\
& BLM & 0.15 & 0.03 & 0.19 & \\
& HH x BLM & -0.01 & 0.004 & -0.14 & \\
\hline
\end{tabular}

Note. $\quad \mathrm{BLM}=$ bottom-line mentality; $\mathrm{HH}=$ honesty-humility. $* p<.001$

To test the hypothesis, a moderated hierarchical regression analysis was conducted, using Hayes' (2013) PROCESS macro. Conscientiousness and self-control were controlled for in the model, and the interaction term was formed from the mean-centered products of the focal predictor $(\mathrm{HH})$ and moderator (BLM). The results of the analysis suggested there was a strong negative interaction between HH and UPB $(\beta=-.14, t(576)=-3.98, p<.001)$, and the addition of the interaction term into the model, was able to account for a significant amount of variance over and above that of $\mathrm{HH}$, conscientiousness, BLM, and self-control, $\Delta R 2=.02, F(1,576)=15.85, p$ $<.001$. The nature of the interaction effect was examined further using a simple slopes analysis as well as graphing the interaction, which can be found below in figure 2, using values of BLM at the mean as well as one standard deviation above and below the mean. 


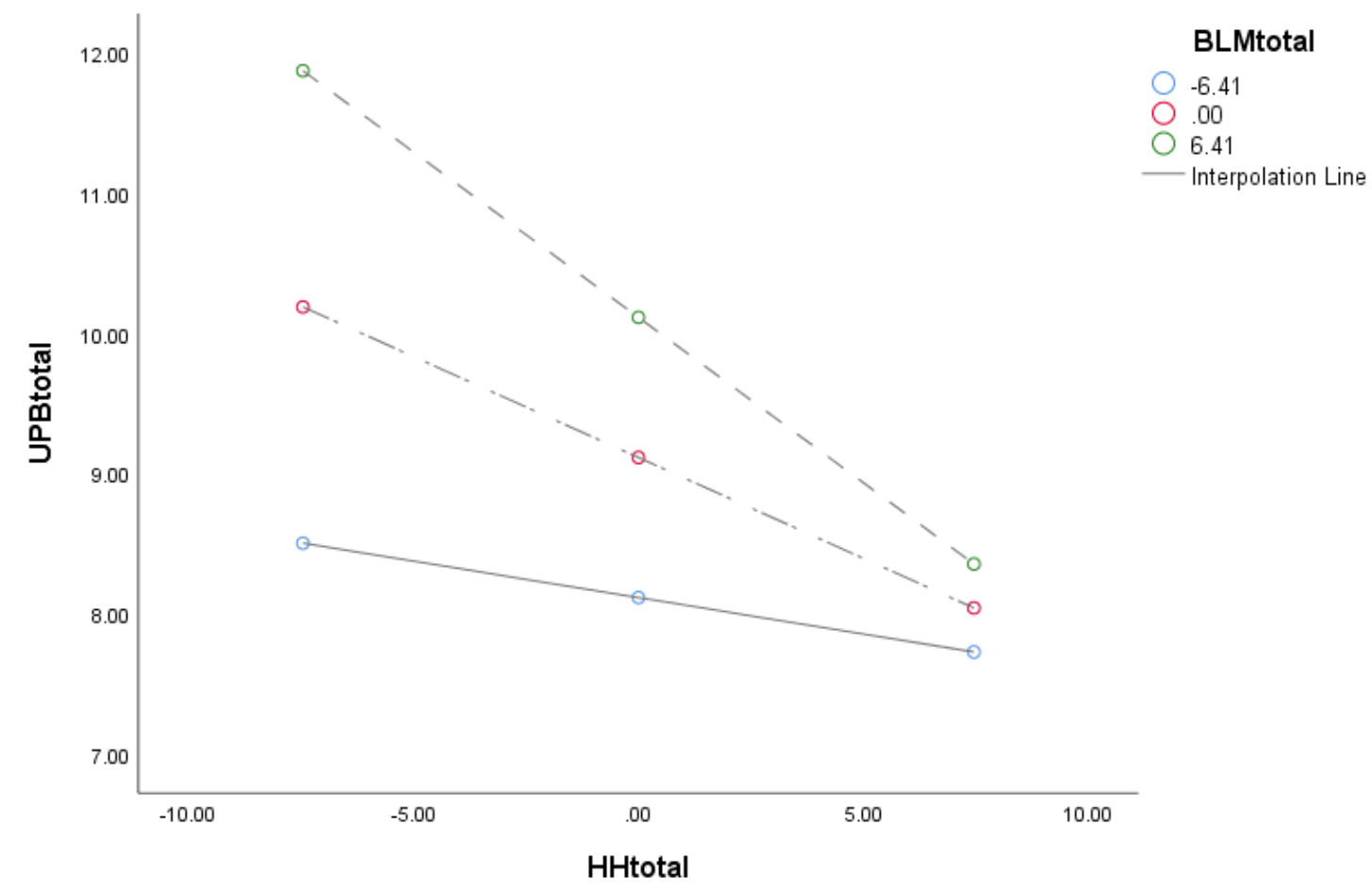

Figure 2. The conditional effect of honesty-humility at high, moderate, and low levels of bottom-line mentality on unethical pro-organizational behavior.

The analysis of the slopes revealed that the relationship between HH and UPB was strongest for those who perceived higher levels of BLM at their company $(\beta=-.23, p<.001)$ than those who perceived moderate $(\beta=-.14, p<.001)$ and lower $(\beta=-.05, p=.11)$ levels of BLM. Thus, there were strong negative relationships between those who perceived moderate to high levels of BLM at their organizations, compared to a non-significant one for those who perceived low levels of BLM. Thus, hypothesis 5a was supported. 


\section{Hypothesis 5b - BLM Moderates Self-Control and UPB}

The second moderated hierarchical regression analysis examined hypothesis $5 \mathrm{~b}$, using Hayes' (2013) PROCESS macro. The hypothesis asserted that the relationship between selfcontrol and UPB would be moderated by BLM, such that individuals with low levels of selfcontrol would be significantly more likely to commit UPB when placed in an environment with high degrees of BLM than those with higher levels of self-control. The interaction term was formulated using the mean-centered cross products of the focal predictor (self-control) and moderator (BLM). The results of the analysis can be found below in Table 3.

Table 3

Hierarchical Regression Analysis Testing the Moderating Effect of Bottom-line Mentality on Self-Control and Unethical Pro-Organizational Behavior

\begin{tabular}{|c|c|c|c|c|c|}
\hline Model & Predictor & $B$ & $S E B$ & $\beta$ & $\Delta R 2$ \\
\hline \multirow[t]{4}{*}{1} & Conscientiousness & -0.24 & 0.04 & $-0.3 *$ & $.28 *$ \\
\hline & Self-Control & -0.03 & 0.03 & -0.05 & \\
\hline & $\mathrm{HH}$ & -0.13 & 0.03 & $-0.19^{*}$ & \\
\hline & BLM & 0.16 & 0.03 & $0.19 *$ & \\
\hline \multirow[t]{5}{*}{2} & Conscientiousness & -0.23 & 0.04 & $-0.29 *$ & $0.03 *$ \\
\hline & Self-Control & -0.04 & 0.03 & -0.07 & \\
\hline & $\mathrm{HH}$ & -0.13 & 0.03 & $-0.19 *$ & \\
\hline & BLM & 0.14 & 0.03 & $0.18 *$ & \\
\hline & $\begin{array}{l}\text { Self-Control x } \\
\text { BLM }\end{array}$ & -0.01 & 0.003 & $-0.18^{*}$ & \\
\hline
\end{tabular}

The initial regression model, with BLM, self-control, conscientiousness, and HH as predictors was able to account for a significant amount of variance in UPB, $R^{2}=.28, F(4,577)=$ 57.3, $p<.001$. However, with the addition of the interaction term in step 2 , the model was able to account for a significant degree of variance in UPB, over and above the effects of the previous 
predictors, $\Delta R^{2}=.03, F(1,576)=27.36, p<.001$. The interaction term itself had a strong negative relation to UPB, $\beta=-.18, t(576)=-5.23, p<.001$. The nature of the interaction effect was examined further using a simple slopes analysis as well as graphing the interaction, which can be found below in figure 3, using values of BLM at the mean as well as one standard deviation above and below the mean.

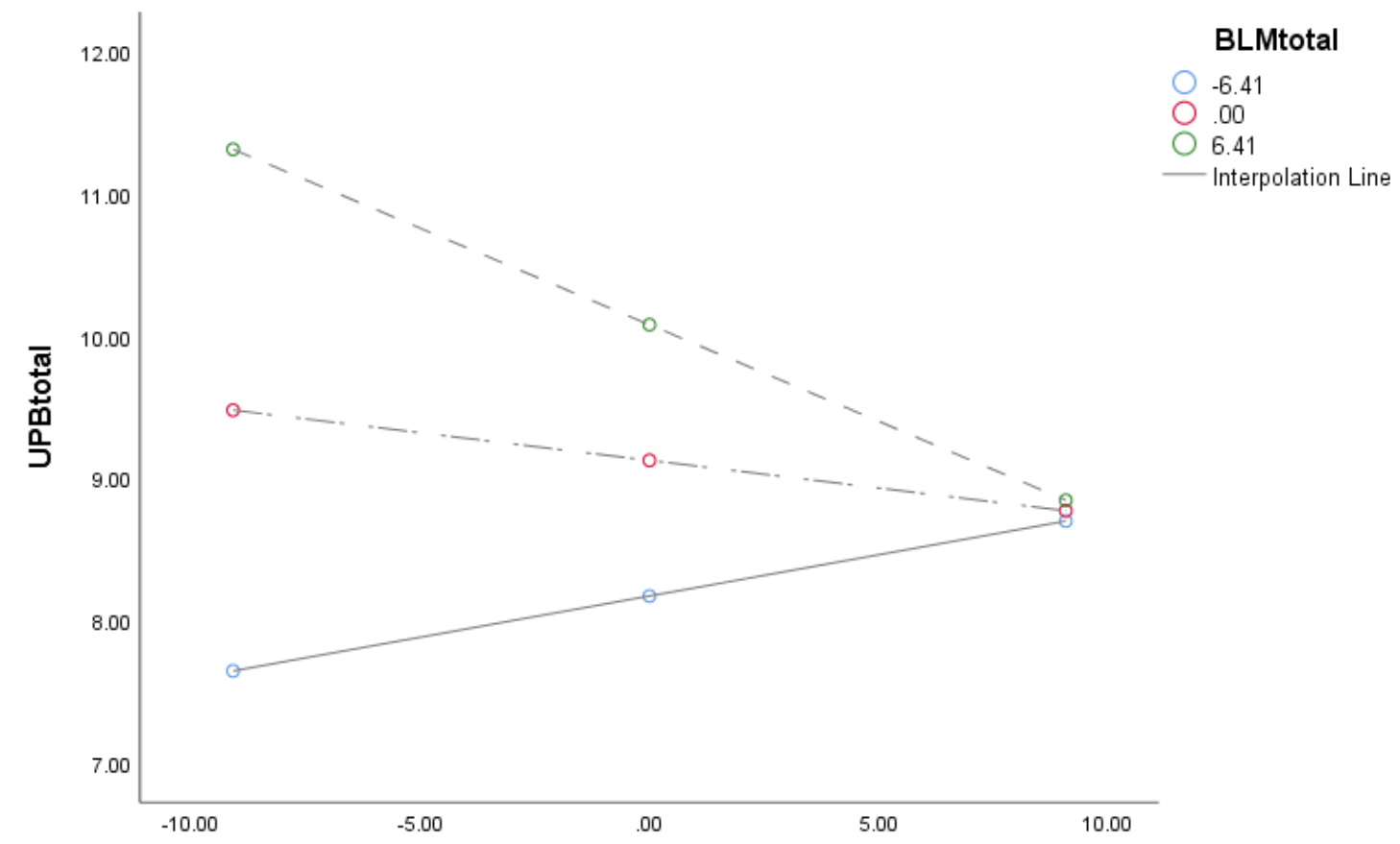

Figure 3. The conditional effect of self-control at high, moderate, and low levels of bottom-line mentality on unethical pro-organizational behavior.

The examination of the slopes revealed that the relationship between self-control and UPB was stronger for those who perceived the highest levels of BLM at their organization $(\beta=-.13, p=$ $.001)$ compared to those who perceived lower levels of $\operatorname{BLM}(\beta=.05, p=.04)$. Interestingly, the relation between self-control and UPB was non-significant at moderate levels of BLM $(\beta=-.04$, $p=.15)$. Thus, hypothesis $5 \mathrm{~b}$ was partially supported. 


\section{Discussion}

The current study sought to investigate the proposed linkages between an employees' individual trait differences, their perceptions of their coworkers' BLM, and UPB, using a crosssectional design. Overall, the study's results seemed to support the notion that when employees with particular traits (i.e. honesty-humility, self-control) are placed in certain environments (i.e. BLM), they will be more likely to commit acts of UPB. Additionally, it was found that employees' who engage in higher levels UPB may also be more likely to engage in higher levels of CWB as well, with the study finding a strong, positive relationship between these two deviant behaviors. However, despite having found empirical support for the conclusions mentioned above, it is important to note that not all of the study's hypothesized relations were fully supported. Specifically, the hypothesized mediation between self-control on the relationship between conscientiousness and UPB, failed to reach significance. Additionally, the hypothesized moderation between self-control and UPB was partially supported, with low levels of BLM suppressing UPB among individuals who were low on self-control. The theoretical implications of these findings will be discussed in further detail below.

As had been discussed earlier, the CWB and UPB constructs share many conceptual similarities. Some of these similarities included the fact that both behaviors result in harm either to those within the organization or its external stakeholders, and in doing so, seem to violate key societal values and norms (Donaldson \& Dunfee, 1994). Beyond these purely conceptual similarities though, UPB and CWB had been found in previous studies to be positively related to each other, as well as having shared similar antecedents, such as Machiavellianism and psychological entitlement (Castille, Buckner, \& Thoroughgood, 2016; Greenbaum et al., 2017;

Lee et al., 2017; Umphress \& Bingham, 2011). The results of the current study found support for 
the notion that UPB and CWB may not be as different from one another as had been suggested previously, due to their common sets of antecedents (Umphress, Mitchell, \& Bingham, 2010). This similarity can be attributed to the current set of findings, which identified a strong, positive correlation between the two variables. This result suggests that individuals who are more likely to engage in high degrees of CWB are also likely to report higher levels of UPB. Furthermore, exploratory post-hoc analyses found that each of the study's antecedents, which included selfcontrol, conscientiousness, $\mathrm{HH}$, and BLM, all maintained strong relations (in similar directions) to both constructs. Given the results for these apriori and post hoc analyses, it is imperative that future studies continue to explore additional antecedents that CWB and UPB may have in common, whether they be individual differences (i.e. traits) or particular characteristics of the employees' environment (i.e. BLM).

One trait antecedent that was found to have a strong, negative correlation to UPB and CWB was conscientiousness. This result supports previous findings in the literature that had found conscientiousness to be a robust predictor of various types of deviant acts, such as CWB as well as those that found it to be one of the primary constructs that integrity tests tap into (Bakker, Demerouti, \& ten Brummelhuis, 2012; Berry, Ones, \& Sackett, 2007; Marcus, Lee, \& Ashton, 2007; Salgado J. F., 1997). This particular finding is important to the UPB literature though, because it identified a trait predictor of UPB, that had not been previously investigated. Given the dearth of studies on UPB's relation to traits, it is important that future studies continue to explore these particular individual difference variables. For example, one such linkage one could examine may include the nature of the relationship between particular facets of conscientiousness and UPB. In this vain, the current study attempted to examine what specific aspects of the somewhat broad conscientiousness trait would make someone more or less likely 
to engage in UPB. Drawing upon findings from the literature on criminology and Gottfredson and Hirchi's (1990) theory of self-control, it was hypothesized that conscientiousness' relation to UPB may be explained through one's ability to self-regulate. However, in contrast to previous studies that had found a statistically significant relation between self-control and deviant acts (Gino, Schweitzer, Mead, and Ariely, 2011; Marcus \& Schuler, 2004; Blickle, Schlegel, Fassbender, and Klein, 2006), the current study was unable to detect a significant relationship between self-control and UPB once conscientiousness had been accounted for. Following this surprising finding, a post-hoc hierarchical regression analysis was run in which it was discovered that once the other variables in the study (i.e. BLM, HH, conscientiousness) had been entered into the model, self-control failed to reach significance. When considering these findings, along with conscientiousness' and self-control's strong correlation, it seems that self-control may have been accounting for much of the same variance in UPB as conscientiousness. Thus, despite earlier findings regarding self-control and its relation to criminal acts, it would seem that in the context of UPB, self-control may have been subsumed under the broader conscientiousness construct. Therefore, future studies examining the role of conscientiousness as it relates to UPB may benefit from further exploring what specific dimensions of the construct are most related to UPB. By pin-pointing these specific dimensions of conscientiousness, one can add theoretical clarity as to what it is about this particular trait that makes someone less likely to engage in these types of acts. Beyond self-control and conscientiousness' relations to UPB though, another trait that was found to have a strong relation to UPB, in the current study, was HH.

$\mathrm{HH}$, a trait that was drawn from the HEXACO model of personality, describes one's propensity to utilize deception for self-gain (Ashton et al., 2005 \& Hillbig, 2010). Like conscientiousness, $\mathrm{HH}$ was a trait that had been shown to be a robust predictor of many types of 
deviant acts (Lee, Ashton, and Shin, 2005; Lee, Ashton, and de Vries, 2005; Ashton \& Lee, 2008b; Zettler and Hillbig, 2010). An important theoretical contribution of the current study was that HH was found to be linked UPB, as well. Specifically, it was discovered that those individuals who have higher degrees of $\mathrm{HH}$ were less likely to engage in UPB than those individuals who had reported lower levels of HH. Given the particular items on the UPB scale, such as one's willingness to lie to protect their company's image, this strong, negative relation makes sense empirically as well as intuitively. However, beyond the strong negative correlations that were found among $\mathrm{HH}$ and conscientiousness to UPB, it was discovered that certain elements of the environment are likely to facilitate and even suppress acts of UPB, especially among those individuals who possess a predisposition to engage in unethical behaviors.

One such situational factor that was found, in the current study, to enhance the expression of one's trait HH, was an employee's perceptions of BLM at their company. These perceptions of BLM reflected the extent to which individual employees' perceived others at their workplace to value the bottom-line outcome over everything else, such as following the rules or considering the consequences their actions may have on others (Greenbaum, Eissa, \& Mawritz, 2012). Thus, when individuals with low $\mathrm{HH}$ were in an environment in which they perceived cues that insinuated to them that attaining the desired business outcome was more important than anything else, such as rules or ethics, they were more likely themselves to engage in UPB. This similar faciliatory effect was also observed for individuals who were low on self-control

In the current study, individuals who were low on self-control were found to be more likely to engage in UPB when their BLM perception was high versus when it was low. In fact, it was found that among low self-control individuals, low levels of BLM worked to suppress UPB. This unexpected finding suggests BLM has differential effects (trait activation or suppression), 
depending on the extent to which it is perceived at the company. These findings, support one of the central tenants of TAT, which states that particular cues from an employees' work environment may enhance or suppress the expression of particular traits (Tett \& Burnett, 2003). Therefore, it would seem that BLM cues acted as a trait activator or suppressor, depending on the levels of self-control an employee possesses. However, it should be noted that among low HH individuals, this suppression effect was not observed. In other words, low HH employees selfreported they were engaging in more UPB, on average, than low self-control employees when they were in similar environments. These differences may have been due to the very nature of the $\mathrm{HH}$ and self-control constructs. Perhaps individuals who are low on trait $\mathrm{HH}$, which reflects a tendency to cheat and exploit others, are more likely to engage in UPB regardless of the environment they're in. For instance, in Castille et al. (2016), it was found that BLMCP failed to moderate the relation between Machiavellianism and willingness to engage in UPB. In this study, the authors speculated that Machiavellian employees were already more likely to engage in UPB, regardless of the social norms governing behavior at their organizations. Moreover, they suggested that the negative relation between Machiavellianism and UPB was so strong, perhaps there was little room for an interaction to take place. However, despite the null finding reported in Castille et al., in the current study, it was found that BLM did still enhance the relation between HH and UPB, it just didn't work to suppress it like it did self-control. Thus, it would seem that more research is needed to further explore this complex relationship between BLM perceptions and $\mathrm{HH}$.

In response to Kins et al.'s (2010) call to identify more situational moderators in the literature on UPB, this study examined the extent to which an employee's perception of their coworker's BLM may facilitate acts of UPB. Like UPB, BLM is a relatively new construct that 
had been first proposed by Greenbaum, Mawritz, and Eissa (2012). In their original study, they found that employees' perception of their supervisor's BLM to be positively related to that employees' subsequent social undermining behaviors. In the current study, an employees' perception of BLM at their workplace was found to be positively related to UPB. This finding reinforces the notion that BLM may be linked to multiple forms of deviant behavior in organizations. Moreover, when viewed through the lens of TAT, these findings would suggest that when employees perceive a coworker's or supervisor's behavioral cues to indicate they ultimately value the bottom-line outcome over and above everything else, they will be more likely themselves to engage in acts that achieve that bottom-line outcome. This hypothesis was examined in the current study, with employee perceptions of coworker BLM being found to moderate the relation between contentiousness and UPB as well as HH and UPB. The nature of these interaction effects was similar, with individuals who reported to have been low on these respective traits being more likely to have engaged in UPB than those who were not. Thus, it would seem that for individuals who are low on conscientiousness or $\mathrm{HH}$, that if they were in an environment in which they perceived their other coworkers to value the bottom-line outcome of their actions, that they would be more likely to express those traits as well. These findings highlight the importance of examining situational variables as they relate to the employees' immediate work environment. Future studies should continue to probe for potential moderators of UPB, so that a more comprehensive understanding of the ways in which employee individual differences may interact with situational factors can be obtained. The practical implications of the study's findings will be discussed below. 


\section{Practical Implications}

The findings from the current study have many practical implications for organizations.

Overall, companies should address the issue of UPB from various angles. First, organizations should try to reduce instances of UPB in the selection process. Specifically, measures should be developed that tap into an applicants' conscientiousness and $\mathrm{HH}$, which were shown, in the current study, to be highly related to UPB. In measuring each of these respective traits, organizations may be able to screen out applicants before they are hired based on their propensity to engage in UPB. Moreover, in measuring these traits, companies may also be able to reduce instances of other forms of deviant behavior, such as $\mathrm{CWB}$, due to $\mathrm{HH}$ and conscientiousness' relations to similar constructs that have been shown to be harmful to the organization as well as its external stakeholders. Therefore, instituting cost-effective preemployment measures that tap into conscientiousness and HH should serve to protect the organization's bottom-line, by helping them avoid some of the negative consequences of UPB, such as litigation.

Another strategy an organization may implement would be to consistently measure employees' levels of BLM. For example, through a relatively short 4-item survey (i.e. Greenbaum, Eissa, \& Mawritz, 2012), companies could keep a pulse on whether their culture is facilitating a BLM among their employees, which was shown in the current study to facilitate acts of UPB, especially on employees who were low in HH and conscientiousness. This strategy is practical, because it is more than likely not going to be feasible for an organization to able to change an employee's personality traits (i.e. conscientiousness, HH). Thus, through measuring levels of BLM at their company, employers can detect an issue early on and develop an intervention to address it. 
One intervention that organizations could employ may focus on the managers' levels of BLM. In Greenbaum et al (2012)., for instance, it was shown that if an employees' supervisor had high levels of BLM, that the employee would be more likely to have higher levels of BLM as well. Therefore, by addressing a supervisor's own BLM, an organization may, in turn, be able to reduce the subordinate's BLM. This top-down approach to treating BLM in companies is relevant, especially when considering the current study's results, which demonstrated that an individual employee will be more likely to have adopted a BLM if their coworkers have been reported to have a high BLM. Therefore, by reducing the supervisor's BLM, their subordinates may be less likely to adopt an approach which emphasizes the bottom-line outcome (i.e. money), which may reduce the likelihood that any individual employee adopts this kind of mindset. In other words, teaching managers about the potential moral and financial consequences of BLM may have on the company and its stakeholders, due to its relationship to UPB, and how their actions may be communicating this type of mindset, may lead to a reduction in both BLM and in UPB.

\section{Limitations}

The study has a few notable limitations, such as those that related to the fact that it used a cross-sectional design. Cross-sectional designs are convenient, because they allow for data to be collected at a single time-point. However, it limits the conclusions that can be drawn from the findings, such as those that relate to predicting an employee's UPB from their measurements on particular traits, such as $\mathrm{HH}$ and conscientiousness. For instance, even though strong negative correlations were found between the study's trait predictors and UPB, it is difficult to determine whether these traits are truly predictive of UPB, given that the data was collected at a single 
point in time. Thus, future studies examining UPB would benefit from utilizing a design in which data is collected across numerous points in time (i.e. longitudinal, time-lagged).

Another notable limitation was that the data was collected using entirely self-report measures, which can be susceptible to biased responding, such as social desirability (Taylor, 1961). Furthermore, this reliance on self-report measures is especially important when considering the nature of the construct that is being measured (UPB), which is viewed as being socially deviant and could even be illegal in some instances. Additionally, the use of self-report measures may have conflated the correlations that were observed between the study's variables through common method variance (Campbell \& Fisk, 1959; Fiske, 1982). Thus, even though the correlations among the study's variables were very high, this finding may have been due to the artifactual covariance shared by the two measures, due to participant's tendency to respond to similar items in a consistent matter (Podsakoff \& Organ, 1986).

Lastly, the current study utilized a revised version of Umphress et al.'s (2010) original scenario-based UPB measure, where participants were asked to rank the extent to which they had engaged in actual UPBs while at their place of work. However, depending on the particular work environment and position the participate held at the time of the study, they may not have had the chance to engage in certain acts of UPB that were included in the measure. For example, one of the items on the revised measure asks, "because my organization needed me to, I have given a good recommendation on the behalf of an incompetent employee in the hope that the person will become another organization's problem instead of my own." Although this item may be relevant to someone who is currently in a managerial position, it is not applicable to someone who is not currently working as a manager. Therefore, the individual for which that item is not applicable to, would likely have responded with a score of 0 , suggesting they had never engaged in that 
behavior before. This type of responding to items that are not applicable to the participant's current job or work environment, may lead to a low base-rate in UPB. This low base-rate can be an issue, because it may lead to an overly skewed distribution of responses on UPB, with most participants indicating that they engage in small amounts of UPB when in reality they do not; their low response rates may have simply been due to the items not being applicable to them. However, it should be noted that this issue is not unique to the UPB literature, but according to Bowling in Gruy's (2010), it is one of the common limitations that faces general measures of deviant behaviors, such as Bennett and Robinson's (2000) measure of CWB. Therefore, Bowling and Gruy's (2010) recommended in their review on measurement practices in CWB, that studies utilize context-specific measures. Therefore, future studies in UPB would benefit from developing context-specific measures, which should help increase the respondent's base-rate, since they would include more items that are relevant to the particular job position. 


\section{REFERENCES}

Angleitner, A., \& Ostendorf, F. (1989). Personality factors via self and peer-ratings based on a respresentative sample of German t rait descriptive terms. First European Congress of Psychology. Amsterdam.

Ashton, M. C., \& Lee, K. (2009). The HEXACO: A short measure of the major dimensions of personality. Journal of Personality Assessment, 91, 340-345.

doi:10.1080/002238902935878

Ashton, M. C., Lee, K., \& de Vries, R. E. (2014). The HEXACO honesty-humility, agreeableness, and emotionality factors: A review of research and theory. Personality and Social Psychology Review, 18(2), 139-152. doi:10.1177/1088868314523838

Ashton, M. C., Perugini, M., de Vries, R. E., Boies, K., Lee, K., Szarota, P., . . Raad, B. D. (2004). A sixth factor structure of personality-descriptive adjectives: Solutions from psycholexical studies in seven languages. Journal of Personality and Social Psychology, 86(2), 356-366. doi:10.1037/0022-3514.86.2.356

Bakker, A. B., Demerouti, E., \& ten Brummelhuis, L. L. (2012). Work engagement, performance, and active learning: The role of conscientiousness. Journal of Vocational Behavior, 80, 555-564.

Balliet, D., Wu, J., \& De Dreu, C. K. (2014). Ingroup favoritism in cooperation: A meta-analysis. Psychological Bulletin, 140, 1556-1581. doi:http://dx.doi.org/10.1037/a0037737

Barney, J. B. (1991). For resources and sustained competitive advantage. Journal of Management, 17, 99-120. doi:http://dx.doi.org/10.1177/0149206391017001098 
Barrick, M. R., Mount, M. K., \& Judge, T. A. (2001). Personality and performance at the beginning of the new millennium: What do we know and where do we go next? International Journal of Seletion and Assessment, 9, 9-30.

Berry, C. M., Ones, D. S., \& Sackett, P. R. (2007). Interpersonal deviance, organizational deviance, and their common correlates: A review and meta-analysis. Journal of Applied Psychology, 92(2), 410-424. doi:10.1037/0021-9010.92.2.410

Bolton, L. R., Becker, L. K., \& Barber, L. K. (2010). Big Five trait predictors of differential counterproductive work behavior dimensions. Personality and Individual Differences, 49, $537-541$.

Bowling, N. A., \& Gruys, M. L. (2010). Overlooked issues in the conceptualization and measurement of counterproductive work behavior. Human Resource Management Review, 20, 54-61.

Campbell, D. T., \& Fisk, D. W. (1959). Convervent and discriminant validation by multitraitmultimethod matrix. Psychological Bulletin, 56, 81-105.

Castille, C. M., Buckner, J. E., \& Thoroughgood, C. N. (2016). Prosocial citizens without a moral compass? Examining the relationship between Machiavellianism and unethical pro-organizational behavior. Journal of Business Ethics, 1-12. doi:10.1007/s10551-0163079-9

Ceschi, A., Sartori, R., Dickert, S., \& Costantini, A. (2016). Grit or honesty-humility? New insights into the moderating role of personality between the health impairment process and counterproductive work behavior. frontiers in Psychology, 7(1799), 1-11. doi:10.3389/fpsyg.2016.01799 
Chen, M., Chen, C. C., \& Sheldon, O. J. (2016). Relaxing moral reasoning to win: How organizational identification relates to unethical pro-organizational behavior. Journal of Applied Psychology, 101(8), 1082-1096. doi:http://dx.doi.org/10.1037/ap10000111

Coffin, B. (n.d.). Breaking the silence on white collar crime. Risk Management, 8.

Colquit, J. A., Scott, B. A., \& Shaw, J. C. (2006). Justice and personality: Using integrative theories to derive moderators of justice effects. Organizational Behavior and Human Decision Processes, 100, 110-127. doi:10.1016/j.obhdp.2005.09.001

Costa, P. T., \& McCrae, R. R. (1992). Revised NEO Personality Inventory (NEO-PI-R) and NEO Five Factor (NEO-FFI) Inventory professional manual. Odessa: Psychological Assessment Resources.

Coyne, I. (2010). Assessing the bipolar nature of productive and counterproductive behaviour at work. Economic and Social Research Council.

Dalal, R. S. (2005). A meta-analysis of the relationship between organizational citizenship behavior and counterproductive work behavior. Journal of Applied Psychology, 90(6), 1241-1255. doi:10.1037/0021-9010.90.6.1241

De Raad, B., Hendriks, A. A., \& Hofstee, W. K. (1992). Towards a refined structure of personality traits. European Journal of Personality, 6, 301-319.

Donaldson, T., \& Dunfee, T. W. (1994). Toward a unified conception of business ethics: Integrative social contracts theory. Academy of Management, 19, 252-284.

Dunlop, P. D., \& Lee, K. (2004). Workplace deviance, organizational citizenship behavior, and business unit performance: The bad apples do spoil the whole barrel. Journal of Organizational Behavior, 25, 67-80. 
Effelsberg, D., \& Solga, M. (2015). Transformational leaders' in-group versus out-group orientation: Testing the Link between leaders' organizational identifcation, their willingness to engage in unethical pro-organizational behavior, and follower perceived transformational leadership. Journal of Business Ethics, 126(4), 581-590. doi:10.1007/s10551-013-1972-z

Effelsberg, D., Solga, M., \& Gurt, J. (2014). Transformational leadership and follower's unethical behavior for the benefit of the company: A two-study investigation. Journal of Business Ethics, 81-93. doi:10.1007/s10551--13-1644-z

Festinger, L., \& Carlsmith, J. M. (1957). Cognitive consequences of forced compliance. Abnormal Social Psychology, 58, 203-211.

Fiske, D. W. (1982). Convergent discrimination validation in measurements and research strategies. In D. Brinberg, \& L. Kidder, New directions for methodology for social and behavioral science: Forms of validity in research (pp. 77-92). San Francisco: JosseyBass.

Fox, S., Spector, P. E., \& Miles, D. (2001). Counterproductive work behavior (CWB) in response to job stressors and organizational justice: Some mediator and moderator tests for autonomy and emotions. Journal of Vocational Behavior, 59, 2910-309. doi:10.1006/jvbe.2001.1803

Frank, R., Bryan-Low, C., Pacelle, M., Smith, R., Berman, D., Mollenkamp C., \& Young, S. (2003, October 3). Scandal scorecard. The Wall Street Journal, p. B4.

Gibney, A. (Director). (2018). Hard NOx [Motion Picture]. 
Gino, F., Schweitzer, M. E., Mead, N. L., \& Ariely, D. (2011). Unable to resist: How self-control promotes unethical behavior. Organizational Behavior and Human Decision Processes, $115,191-203$.

Goldberg, L. R. (1992). The development of markers for the Big-Five factor structure. Psychological Assessment, 4, 26-42. doi:10.1037/1040-3590.4.1.26

Goldberg, L. R. (1993). The structure of phenotypic personality traits. American Psychologist, 48, 26-34.

Graham, K. A., Ziegert, J. C., \& Capitano, J. (2015). The effect of leadership style, framing, and promotion regulatory focus on unethical pro-organizational behavior. Journal of Business Ethics, 126(3), 423-436. doi:10.1007/s10551-013-1952-3

Greenbaum, R. L., Mawritz, M. B., \& Eissa, G. (2012). Bottom-line mentality as an antecedent of social undermining and the moderating roles of core self-evaluations and conscientiousness. Journal of Applied Psychology, 97(2), 343-359. doi:10.1037/a0025217

Greenberg, J. (1990). Employee theft as a reaction to underpayment inequity: The hidden cost of pay cuts. Journal of Applied Psychology, 75, 561-568.

Griffin, R. W., \& Lopez, Y. (2005). "Bad behavior" in organizations: A review and typology of future research. Journal of Management, 31(6), 988-1005. doi:10.1177/01492063052279942

Gruys, M. L., \& Sackett, P. R. (2003). Investigating the dimensionality of counterproductive work behavior. International Journal of Selection and Assessment, 11(1), 30-42.

Harper, D. (1990). Spotlight abuse-Save profits. Industrial Distribution, 79, pp. 47-51. 
Hilbig, B. E., \& Zettler, I. (2009). Pillars of cooperation: Honesty-Humility. social orientations, and economic behavior. Journal of Research in Personality, 43, 516-519.

Hogan, J., \& Ones, D. S. (1997). Conscientiousness and integrity at work. In R. Hogan, J. A. Johnson, \& S. R. Briggs, Handbook of personality psychology (pp. 849-870). San Diego: Academic Press.

Hogan, R., \& Blake, R. J. (1996). Vocational interests: Matching self-concept with the work environment. In K. R. Murphy, Individual differences and behavior in organizations (pp. 89-144). San Francisco: Jossey-Bass.

Horn, J., Nelson, C. E., \& Brannick, M. T. (2004). Integrity, conscientiousness, and honesty. Psychological Reports, 95, 27-38. doi:10.2466/pr0.95.1.27-38

Jensen, J. M., \& Patel, P. C. (2011). Predicting counterproductive work behavior from the interaction of personality traits. Personality and Individual Differences, 51, 466-471.

Kalshoven, K., van Dijk, H., \& Boon, C. (2016). Why and when does ethical leadership evoke unethical follower behavior? Journal of Managerial Psychology, 31(2), 500-515. doi:10.1108/JMP-10-2014-0314

Kong, D. T. (2016). The pathway to unethical pro-organizational behavior. Personality and Individual Differences, 93, 86-91.

Lee, A., Schwartz, G., Newman, A., \& Legood, A. (2017). Investigating when and why psychological entitlement predicts unethical pro-organizational behavior. Journal of Business Ethics. doi:10.1007/s10551-017-3456-z

Lee, K., \& Ashton, M. C. (2005). Psychopathy, Machiavellianism, and Narcissism in the FiveFactor Model and the HEXACO model of personality structure. Personality and Individual Differences, 38, 1571-1582. 
Lee, K., Ashton, M. C., \& Shin, K.-H. (2005). Personality Correlates of Workplace Anti-Social Behavior. Applied Psychology: An international review(54), 81-98.

Lee, K., Ashton, M. C., Wiltshire, J., Bourdage, J. S., Visser, B. A., \& Gallucci, A. (2013). Sex, power, and money: Prediction from the Dark Triad and Honesty-Humility. European Journal of Personality, 27, 169-184.

Lockwood, P., Jordan, C. H., \& Kunda, Z. (2002). Motivation by positive or negative role models: Regulatory focus determines who will best inspire us. Journal of Personality and Social Psychology, 83, 854-864.

Magnusson, D. (1990). Personality deveelopment from an interactionist perspective. In L. A. Pervin, Handbook of Personality: Theory and Research (pp. 193-224). New York: Guilford Press.

Marcus, B., Lee, K., \& Ashton, M. C. (2007). Personality dimensions explaining relationships between integrity tests and counterproductive work behavior: Big Five, or one in addition? Personnel Psychology, 60, 1-34.

Marcus, B., Taylor, O. A., Hastings, S. E., Sturm, A., \& Weigelt, O. (2016). The structure of counterproductive work behavior: A review, a structural meta-analysis, and a primary study. Journal of Management, 42(1), 203-233. doi:10.1177/014920633503019

McFerran, B., Aquino, K., \& Duffy, M. (2010). How personality and moral identity relate to individuals' ethical ideology. Business Ethics Quarterly, 20, 35-56.

Miao, Q., Newman, A., Yu, J., \& Xu, L. (2013). The relationsihp between ethical leadership and unethical pro-organizational behavior: Linear or curvilinear effects? Journal of Business Ethics, 641-653. doi:10.1007/s10551-012-1504-2 
Mischel, W. (1977). The interaction of person and situation. In D. Magnusson, \& N. S. Endler, Personality at the Crossroads: Current Issues in International Psychology (pp. 333-352). Hillsdale: Lawrence Erlbaum Associates, Inc.

Moon, H. (2001). The two faces of conscientiuosness: Duty and achievement striving in escalation of commitment dilemmas. Journal of Applied Psychology, 86, 533-540. doi:10.103/0021-9010.86.3.535

Moore, C., Detert, J. R., Trevino, L. K., Baker, V. L., \& Mayer, D. M. (2012). Why employees do bad things: Moral disengagement and uenthical organizational behavior. Personnel Psychology, 1-48.

Murphy, K. R. (1993). Honesty in the workplace. Belmont, CA: Brooks/Cole.

Murphy, K. R., Myors, B., \& Wolach, A. (2014). Statistical Power Analysis: A Simple and General Model for Traditional and Modern Hypothesis Tests. Taylor \& Francis Group. Retrieved from https://ebookcentral.proquest.com/lib/ilstu/detail.action?doclD=1754641

O'Boyle, Jr., E. H., Forsyth, D. R., Banks, G. C., \& McDaniel, M. A. (2012). A meta nalysis of the Dark Triad and work behavior: A social exchange perspective. Journal of Applied Psychology, 97(3), 557-579. doi:10.1037/a0025679

Ones, D. S., \& Dilchert, S. (2013). Counterproductive work behaviors: Concepts, measurement, and nomological network. In B. A. Geisinger, J. F. Bracken, J. I. Carlson, N. R. Hansen, S. P. Reise, \& M. C. Rodriguez, APA handbook of testing and assessment in psychology: Test theory and testing and assessment in industrial and organizational psychology (pp. 643-659). Washington DC: American Psychological Association. 
Podsakoff, P. M., \& Organ, D. W. (1986). Self-reports in organizational research: Problems and prospects. Journal of Management, 4(12), 531-544. doi:https://doi.org/10.1177/014920638601200408

Rest, J., Narvaez, M., Bebeau, J., \& Thoma, S. J. (1999). Postconventional Moral Thinking: A Neo-Kohlbergian Approach. Mahwah: Lawrence Erlbaum Associates.

Robinson, S. L., \& Bennett, R. J. (1995). A typology of deviant workplace behaviors: A multidimensional scaling study. Academy of Management, 38(2), 555-572.

Sackett, P. R. (2002). The structure of counterproductive work behaviors: Dimensionality and relationships with facets of job performancce. International Journal of Selection and Assessment, 10, 5-11.

Sackett, P. R., \& DeVore, C. J. (2001). Counterproductive behaviors at work. In N. Anderson, S. Ones, H. K. Sinangil, \& C. Viswesvaran, Handbook of industrial, work, and organizational psychology (pp. 145-164). London: Sage.

Salgado, J. F. (1997). The five factor model of personality and job performance in the European Community. Journal of Applied Psychology, 82, 30-43.

Salgado, J. F. (2002). The Big Five personality dimensions and counterproductive work behaviors. International Journal of Selection and Assessment, 10(1/2), 117-125.

Smithikrai, C. (2008). Moderating effect of situational strength on the relationship between personality traits and counterproductive work behavior. Asian Journal of Social Psychology, 11, 253-263. doi:10.1111/j.1467-839X.2008.00265.x

Spector, P. E., \& Fox, S. (2005). The stressor-emotiona model of counterproductive work behavior. In P. E. Spector, Counterproductie work behavior: Investigations of actors and targets (pp. 151-174). Washington, D.C.: American Psychological Association. 
Sykes, G., \& Matza, D. (1957). Tecniques of Neutralization. Amer. Social. Rev, 22(6), 664-670.

Tajfel, H. (1982). Social psychology of intergroup relations. Annuel Review of Psychology, 33, 1-39. doi:http://dx.doi.org/10.1146/annurev.ps.33.020182.000245

Tajfel, H., \& Turner, J. C. (1985). The social identity theory of intergroup behavior. In S. Worchel, \& W. G. Austin, Psychology of intergroup relations (pp. 7-24). Chicago: Nelson-Hall.

Tangney, J. P., Baumeister, R. F., \& Boone, A. L. (2004). High self-control predicts good adjustment, less pathology, better grades, and interpersonal success. Journal of Personality, 72, 271-324. doi:10.1111/j.0022-3506.2004.00263.x

Taylor, J. B. (1961). What do attitude scales measure: THe problem of social desirability. Abnormal and Social Psychology, 62, 386-390.

Tsui, A., \& Wang, D. (2002). Employment relationships from the employer's perspective: Current research and future directions. International Review of Industrial and Organizational Psychology, 17, 77-114.

Umphress, E. E., \& Bingham, J. B. (2011). When Employees Do Bad Things for Good Reasons: Examining Unethical Pro-Organizational Behaviors. Organization Science, 621-640.

Umphress, E. E., Mitchell, M. S., \& Bingham, J. B. (2010). Unethical Behavior in the Name of the Company The Moderating effect of Organizational Identification and Positive Reciprocity Beliefs on Unethical Pro-Organizational Behavior. Journal of Applied Psychology, 769-780. 
Wang, T., Long, L., Zhang, Y., \& He, W. (2017). A social exchange perspective of employeeorganization relationships and employee unethical pro-organizational behavior: The moderating Role of Individual Moral Identity. Journal of Business Ethics, 1-17. doi:10.1007/s10551-018-3782-9

Zettler, I., \& Hilbig, B. E. (2010). Honesty-Humility and a Person-Situation Interaction at Work. European Journal of Personality, 562-582.

Zvonimir, G., \& Ruzojcic, M. (2017). Interaction between implicit aggression and dispositional self-control in explaining counterproductive work behaviors. Personality and Individual Differences, 104, 111-117. 


\section{APPENDIX A: CONSCIENTIOUSNESS SCALE}

\section{Ashton and Lee's (2009) 60-item HEXACO-PI-R scale}

Responses were made on a scale ranging from 1 (strongly disagree) to 5 (strongly agree)

1. I plan ahead and organize things, to avoid scrambling at the last minute.

2. I often push myself very hard when trying to achieve a goal.

3. When working on something, I don't pay much attention to the small details.

4. I make decisions based on the feeling of the moment rather than on careful thought.

5. When working, I sometimes have difficulties due to being disorganized.

6. I do only the minimum amount of work needed to go by.

7. I always try to be accurate in my work, even at the expensive of time.

8. I make a lot of mistakes because I don't think before I act.

9. People often call me a perfectionist.

10. I prefer to do whatever comes to mind, rather than stick to a plan 


\section{APPENDIX B: HONESTY-HUMILITY SCALE}

\section{Ashton and Lee's (2009) 60-item HEXACO-PI-R scale}

Responses were made on a scale ranging from 1 (strongly disagree) to 5 (strongly agree)

1. I wouldn't use flattery to get a raise or promotion at work, even if I thought it would succeed.

2. If I knew that I could never get caught, I would be willing to steal a million dollars.

3. Having a lot of money is not especially important to me.

4. I think that I am entitled to more respect than the average person is.

5. If I want something from someone, I will laugh at that person's worst jokes.

6. I would never accept a bribe, even it if were very large.

7. I would get a lot of pleasure from owning expensive luxury goods.

8. I want people to know that I am an important person of high status.

9. I wouldn't pretend to like someone just to get that person to do favors for me.

10. I'd be tempted to use counterfeit money, if I were sure I could get away with it. 


\section{APPENDIX C : BOTTOM-LINE MENTALITY SCALE}

\section{A revised version of Greenbaum, Eissa, and Mawritz's (2012) four-item Bottom Line}

\section{Mentality Scale}

Responses were made on a scale ranging from 1 (strongly disagree) to 7 (strongly agree)

Indicate the extent to which people here:

1. Are solely concerned with meeting the bottom line.

2. Only care about the business.

3. Treat the bottom line as more important than anything else.

4. Care more about profits than well-being.

Copyright @ 2012 American Psychological Association. Adapted with permission. No further reproduction or distribution is permitted without written permission from the American Psychological Association. 


\section{APPENDIX D : COUNTERPRODUCTIVE WORK BEHAVIOR SCALE Bennett and Robinson's (2000) Counterproductive Work Behavior Scale}

Responses were made on a scale ranging from 1 (strongly disagree) to 5 (strongly agree)

Interpersonal Deviance:

1. Made fun of someone at work.

2. Said something hurtful to someone at work.

3. Made an ethnic, religious, or racial remark at work.

4. Cursed at someone at work.

5. Played a mean prank on someone at work.

6. Acted rudely toward someone at work.

7. Publicly embarrassed someone at work.

Organizational Deviance:

1. Taken property without permission.

2. Spent too much time fantasizing or daydreaming instead of working.

3. Falsified a receipt to get reimbursed for more than that you spent on business expenses.

4. Taken an additional or longer break than is acceptable at your workplace.

5. Come in late to work without permission.

6. Littered your work environment.

7. Neglected to follow your boss's instructions

8. Discussed confidential company information with an unauthorized person.

9. Intentionally worked slower than you could have worked.

10. Used an illegal drug or consumed alcohol.

11. Put little effort into your work. 
12. Dragged out work in order to get overtime.

Copyright (C) 2000 American Psychological Association. Reproduced with permission. No further reproduction or distribution is permitted without written permission from the American Psychological Association. 
APPENDIX E : REVISED UNETHICAL PRO-ORGANIZATIONAL SCALE

Umphress, Bingham, and Mitchell's (2010) six-item Unethical Pro-Organizational Behavior

Scale

Responses were made on a scale ranging from 1 (strongly disagree) to 7 (strongly agree)

1. Because it was needed, I have concealed information from the public that could be damaging to my organization.

2. Because our organization needed me to, I have withheld issuing a refund to a customer or client accidentally overcharged.

3. Because it helped my organization, I have exaggerated the truth about my company's products or services to customers and clients.

4. Because it benefited my organization, I have withheld negative information about my company or its products from customers and clients.

5. Because it helped my organization, I have misrepresented the truth to my organization look good.

6. Because my organization needed me to, I have given a good recommendation on the behalf of an incompetent employee in the hope that the person would become another organization's problem instead of my own.

Copyright (C) 2010 American Psychological Association. Adapted with permission. No further reproduction or distribution is permitted without written permission from the American Psychological Association. 


\section{APPENDIX F: SELF-CONTROL SCALE}

\section{Tangney, Baumeister, and Boon's (2004) 13-item Brief Self-Control Scale}

Responses were made on a scale ranging from 1 (not at all like me) to 5 (very much like me)

1. I am good at resisting temptation.

2. I have a hard time breaking bad habits.

3. I am lazy.

4. I say inappropriate things.

5. I do certain things that are bad for me, if they are fun.

6. I refuse things that are bad for me.

7. I wish I had more self-discipline.

8. People would say that I have iron self-discipline.

9. Pleasure and fun sometimes keep me from getting work done.

10. I have trouble concentrating.

11. I am able to work effectively toward long-term goals

12. Sometimes I can stop myself from doing something even if I know it is wrong.

13. I often act without thinking through all of the alternatives. 